Golden oldies and silver brains : Deficits, preservation, learning, and rehabilitation effects of music in ageing-related neurological disorders

Sarkamo, Teppo

2018-12

Sarkamo, T \& Sihvonen , A J 2018 , ' Golden oldies and silver brains : Deficits, preservation, learning, and rehabilitation effects of music in ageing-related neurological disorders ' , Cortex , vol. 109 , pp. 104-123 . https://doi.org/10.1016/j.cortex.2018.08.034

http://hdl.handle.net/10138/311678

https://doi.org/10.1016/j.cortex.2018.08.034

cc_by_nc_nd

acceptedVersion

Downloaded from Helda, University of Helsinki institutional repository.

This is an electronic reprint of the original article.

This reprint may differ from the original in pagination and typographic detail.

Please cite the original version. 


\title{
Golden oldies and silver brains: Deficits, preservation, learning, and rehabilitation effects of music in ageing-related neurological disorders
}

\author{
Teppo Särkämö ${ }^{1, *}$ and Aleksi J. Sihvonen ${ }^{1,2}$ \\ ${ }^{1}$ Cognitive Brain Research Unit, Department of Psychology and Logopedics, University of Helsinki, Finland \\ 2Faculty of Medicine, University of Turku, Finland
}

*Corresponding author: Teppo Särkämö, Cognitive Brain Research Unit, Department of Psychology and Logopedics, Faculty of Medicine, University of Helsinki, Siltavuorenpenger 1B, P.O. Box 9, FI-00014 Helsinki, Finland. E-mail: teppo.sarkamo@helsinki.fi

\begin{abstract}
During the last decades, there has been major advances in mapping the brain regions that underlie our ability to perceive, experience, and produce music and how musical training can shape the structure and function of the brain. This progress has fueled and renewed clinical interest towards uncovering the neural basis for the impaired or preserved processing of music in different neurological disorders and how music-based interventions can be used in their rehabilitation and care. This article reviews our contribution to and the state-of-the-art of this field. We will provide a short overview outlining the key brain networks that participate in the processing of music and singing in the healthy brain and then present recent findings on the following key music-related research topics in neurological disorders: (i) the neural architecture underlying deficient processing of music (amusia), (ii) the preservation of singing in aphasia and music-evoked emotions and memories in Alzheimer's disease, (iii) the mnemonic impact of songs as a verbal learning tool, and (iv) the cognitive, emotional, and neural efficacy of music-based interventions and activities in the rehabilitation and care of major ageing-related neurological illnesses (stroke, Alzheimer's disease, and Parkinson's disease).
\end{abstract}

\section{Keywords:}

Music; Rehabilitation; Stroke; Alzheimer's disease; Parkinson's disease 
"Music evokes emotion and emotion can bring its memory". This famous quote from Dr. Oliver Sacks (19332015) elegantly summarizes one of the key facets of music, namely its unique ability to convey and elicit emotions and their close linkage to episodic and autobiographical memories. While this holds true for all of us, the emotional, communicative, and mnemonic impact of music is particularly evident in persons suffering from neurological illnesses affecting verbal expression (aphasia) and memory (dementia). Overall, music is an important source of enjoyment, learning, and well-being in life as well as a rich, powerful, and versatile stimulus for the brain. With the advance of modern neuroimaging techniques during the past decades, we are now beginning to understand better what goes on in the healthy brain when we perceive, experience, and produce music and how the structure and function of the brain can change as a result of musical training and expertise.

The progress in uncovering the neural basis of music has greatly fueled and renewed clinical interest towards music as a neurorehabilitation tool to facilitate recovery and functioning in severe ageing-related neurological illnesses, including stroke, Alzheimer's disease (AD) and other dementias, and Parkinson's disease (PD) (for recent reviews, see Magee, Clark, Tamplin, \& Bradt, 2017; Sihvonen et al., 2017a; van der Steen et al., 2017). Overall, music has the capacity to enhance mood and arousal, facilitate verbal and non-verbal (emotional) communication and social interaction, engage multiple cognitive and motor functions, and provide reward and motivation to learn and train. This makes music a highly versatile and potentially very effective means of rehabilitation, setting it apart from other activities or forms of communication traditionally used in neurological rehabilitation. Societally, this is highly important as the prevalence of stroke (Feigin et al., 2014) and dementia (Prince et al., 2013) are rising rapidly across the world, bringing about massive societal and economical burden (Olesen et al., 2012).

In this review, we will (i) provide a short overview outlining the key brain networks that participate in the processing of music and singing in the healthy brain and then present recent findings on three key music-related research topics in the domain of stroke and dementia: (ii) the neural architecture underlying deficient / preserved processing of music, (iii) the mnemonic impact of songs as a verbal learning tool, and (iv) the cognitive, emotional, and neural efficacy of music-based interventions in rehabilitation and care of stroke, $A D$, and PD. Regarding the last point, this review focuses broadly on different musical leisure activities and interventions involving music listening, instrument playing, singing, or dancing, which are implemented either by music therapists or by the patients themselves, their caregivers, or other rehabilitation personnel (for recent reviews focusing on music formal therapy in this context, please see: Magee et al., 2017; McDermott, Crellin, Ridder, \& Orrell, 2013; van der Steen et al., 2017).

\section{Neural basis of music processing in the healthy brain}

The ability to perceive, enjoy, and produce music is a fundamentally human feature, present across cultures and developing very early in life (Trehub, 2003), with even young infants showing functional specialization for the processing of musical structures, such as tonality and chord categories, in the brain (Perani et al., 2010) as well as spontaneous motor entrainment to musical rhythm (Zentner \& Eerola, 2010). For the human brain, music arguably ranks among the most complex and multidomain stimuli, engaging a large-scale bilateral network of temporal, frontal, parietal, cerebellar, and limbic and paralimbic brain areas associated with multiple parallel cognitive, verbal, motor, and emotional processes.

\subsection{Brain networks underlying music perception in the healthy brain}

The different neural networks engaged by the perception, experience, and production of music are illustrated in Figure 1. The first perceptual stage of this process entails the encoding and analysis of the basic auditory features of music (e.g., pitch, intensity, temporal variation), which takes place along the ascending auditory pathway, from the inner ear to brain stem and thalamus, and projecting to auditory cortical (AC) areas (Hall, Hart, \& Johnsrude, 2003; Skoe \& Kraus, 2010; Zatorre, Belin, \& Penhune, 2002). This latter stage is largely bilateral, engaging both left and right $A C$, although with a degree of lateralization: the right $A C$ is more specialized 
in fine-grained spectral processing and the left AC in rapid temporal processing of sounds (Zatorre \& Belin, 2001; Zatorre et al., 2002). Notably, the thalamus also projects auditory information directly to limbic areas, such as the amygdala and the medial orbitofrontal cortex (LeDoux, 2010; Öngür \& Price, 2000), enabling the rapid analysis of emotional acoustic cues embedded in music.

After the initial low-level perceptual encoding stage, music processing unfolds over multiple spatially distributed networks governing higher-level perceptual, cognitive, motor, and emotional functions. The processing of higherorder musical features (e.g., chords, melody, harmony) following a rule-based syntactic analysis of spectral and temporal fluctuation patterns within the sound stream occurs in a network comprising inferior and medial prefrontal areas, premotor areas, anterior and posterior superior temporal areas, and inferior parietal areas (Alluri et al., 2012; Janata et al., 2002; Patel, 2003; Patterson, Uppenkamp, Johnsrude, \& Griffiths, 2002). The periodic rhythm (beat) of music as well as the motor production of music (e.g., instrument playing, tapping to beat) is further accomplished by a network of motor regions in the frontal motor and premotor cortices, basal ganglia, and cerebellum (Bengtsson et al., 2009; Chen, Penhune, \& Zatorre, 2008; Grahn \& Rowe, 2009; Zatorre, Chen, \& Penhune, 2007). Keeping track of music as it unfolds over time enlists the attention and working memory system in the inferior and dorsolateral prefrontal cortex, the cingulate cortex, and the inferior parietal cortex (Janata, Tillmann, \& Bharucha, 2002; Jerde, Childs, Handy, Nagode, \& Pardo, 2011; Schulze, Zysset, Mueller, Friederici, \& Koelsch, 2011). Recalling long-term memories associated with music engages the episodic memory system, which covers many areas in medial temporal (e.g., hippocampus), parietal (precuneus, angular gyrus), and frontal (dorsomedial and inferior prefrontal) lobe (Ford, Addis, \& Giovanello, 2011; Janata, 2009; Platel, Baron, Desgranges, Bernard, \& Eustache, 2003).

Finally, the affective impact of music and the hedonic pleasure derived from music is closely linked to the dopaminergic emotion and reward network of the brain, involving limbic and mesolimbic structures such as the nucleus accumbens of basal ganglia, the amygdala, the hippocampus, the cingulate cortex, and the orbitofrontal cortex (Blood \& Zatorre, 2001; Koelsch, 2014; Salimpoor, Benovoy, Larcher, Dagher, \& Zatorre, 2011; Zatorre \& Salimpoor, 2013). Importantly, the familiarity and the emotional impact of music seem to be closely intertwined in the brain, as indicated by recent findings that familiar music activates the reward circuitry more than unfamiliar music (Pereira et al., 2011) and enjoyable music activates the episodic memory network more extensively than less positively valenced music during recognition (Altenmüller, Siggel, Mohammadi, Samii, \& Münte, 2014). This has important implications for the preservation on music-evoked emotions and memories in $A D$.

\subsection{Brain networks underlying song perception and singing in the healthy brain}

Neuroimaging studies in healthy subjects have shown that the processing of music and speech share processing resources in many parts of the brain, including temporal, frontal, and parietal areas, but also engage distinct cortical networks [for a Activation Likelihood (ALE) meta-analysis, see LaCroix, Diaz, \& Rogalsky, 2015]. Results from recent functional magnetic resonance imaging (fMRI) studies using univariate and multivariate pattern analysis, which have directly compared natural speech and music processing in the same subjects, indicate that while speech and music both engage bilateral superior temporal areas extensively, speech is processed more ventrolaterally and music more dorsomedially (Angulo-Perkins et al., 2014; Norman-Haignere et al., 2015; Rogalsky et al., 2011; Tervaniemi et al., 2006), suggesting distinct spatial patterns and stages of processing for speech and music within the same temporal network.

Conceptually, songs represent an interesting interface between speech and music, binding lyrics and melody into a unified representation. Thus, the neural processing of songs is a combination linguistic (syntactic, semantic), musical (melodic, rhythmic), domain-general cognitive (attention, memory), vocal-motor, and emotional processing. Evidence from fMRI studies suggests that listening to vocal songs activates bilateral temporal [e.g., superior temporal gyrus (STG), planum temporale] and frontal [e.g., superior frontal gyrus (SFG), premotor cortex] areas as well as subcortical / limbic areas (e.g., hippocampus, striatum, orbitofrontal cortex) more extensively than listening to speech (Callan et al., 2006; Méndez Orellana et al., 2014; Schön et al., 2010; Sharda et al., 2015) or instrumental music (Alluri et al., 2013; Brattico et al., 2011; Lévêque \& Schön, 2015). The perception of vocal melodies also engages the right sensorimotor cortex and its connectivity with other parts of 
the auditory dorsal stream, a key pathway of audio-vocal integration in speech production (Lévêque \& Schön, 2015).

The production of singing entails continuous interaction between two cortical systems, the frontoparietal (dorsal) vocal production pathway and the frontotemporal (ventral) auditory perception pathway (see Figure 1), coupled with the engagement of above-mentioned wide-scale language and music processing networks (Brown, Martinez, Hodges, Fox, \& Parsons, 2004; Callan et al., 2006; Kleber, Veit, Birbaumer, Gruzelier, \& Lotze, 2010; Özdemir, Norton, \& Schlaug, 2006; Zarate, 2013). Compared to speaking, singing activates bilateral (right more strongly than left) superior temporal areas, pre- and post-central gyri, and inferior frontal areas more extensively (Brown, Martinez, Hodges, Fox, \& Parsons, 2004; Callan et al., 2006; Özdemir et al., 2006), which has major clinical implications for aphasia rehabilitation.

\section{Neural architecture underlying deficient / preserved processing of music}

\subsection{Neural basis of musical deficits}

Amusia or tone-deafness refers to severe impairment in the perception and/or production of music caused by abnormal brain development (congenital amusia) or focal brain damage (acquired amusia), most often due to stroke (Peretz, 2016; Stewart, von Kriegstein, Warren, \& Griffiths, 2006). Amusia typically manifests as a deficit in perceiving fine-grained pitch changes within melodies, but also other musical functions (rhythm of timbre perception, musical memory, music-evoked emotions) can be affected (Stewart et al., 2006).

In congenital amusia, structural MRI (sMRI) studies utilizing voxel-based morphometry (VBM) have provided evidence of reduced white matter concentration and abnormalities in grey matter volume / cortical thickness in the inferior frontal gyrus (IFG) and the STG, predominantly in the right (Albouy et al., 2013; Hyde et al., 2006, 2007) but also in the left (Mandell, Schulze, \& Schlaug, 2007) hemisphere. Functionally, evidence from electoencephalography (EEG) and fMRI studies suggests that in congenital amusia the right auditory cortex is normally responsive to pitch changes in melodies and harmonic tones, but consciously attending to and cognitively analyzing this pitch information in right frontal regions, especially in the right IFG, fails due to reduced connectivity between these regions (Hyde, Zatorre, \& Peretz, 2011; Lévêque et al., 2016; Norman-Haignere et al., 2016; Peretz, Brattico, \& Tervaniemi, 2005; Peretz, Brattico, Järvenpää, \& Tervaniemi, 2009; Zendel, Lagrois, Robitaille, \& Peretz, 2015). Interestingly, despite being unable to detect small pitch differences or recognize melodies, congenital amusics are nevertheless able sing pitch intervals in correct directions (Loui, Guenther, Mathys, \& Schlaug, 2008) and recognize song lyrics (Ayotte, Peretz, \& Hyde, 2002), suggesting a dissociation between the melodic and vocal representations or codes in this disorder. Although congenital amusia is considered to be a lifelong condition, recent evidence suggests that it may be malleable to training, as psychophysical pitch discrimination training has been found to lower pitch discrimination thresholds in amusics (Liu, Jiang, Francart, Chan, \& Wong, 2017; Whiteford \& Oxenham, 2018), with carryover effects also to music perception ability (Whiteford \& Oxenham, 2018).

The neuroanatomical basis of acquired amusia has thus far mostly been explored in small-scale lesion studies, which have yielded somewhat inconsistent results regarding the lateralization and precise spatial location of the lesion(s) underlying different types of music perception deficits, with spectral (e.g., pitch, timbre) and temporal (e.g., rhythm, metre) perception deficits being variably reported after temporal, insular, frontal and/or parietal lesions either in the right or left hemisphere (Ayotte, Peretz, Rousseau, Bard, \& Bojanowski, 2000; Kester et al., 1991; Liégeois-Chauvel, Peretz, Babaï, Laguitton, \& Chauvel, 1998; Rosslau et al., 2015; Särkämö et al., 2009; Schuppert, Münte, Wieringa, \& Altenmüller, 2000).

Recently, we reported a set of studies on acquired amusia, which for the first time utilized modern sMRI methods, including voxel-based lesion symptom mapping (VLSM), VBM, and diffusion tensor imaging (DTI) with deterministic tractography and tract-based spatial statistics analyses as well as $\mathrm{fMRI}$ to explore the neural basis acquired amusia and its recovery in a large longitudinal sample of stroke patients ( $N=41-90)$. Amusia was clinically assessed using the Montreal Battery of Evaluation of Amusia (MBEA). The VLSM results (Figure 2A) 
showed that acquired amusia was associated with a lesion pattern comprising right temporal [STG, middle temporal gyrus (MTG)] and striatal (caudate, putamen, globus pallidus) regions as well as the right insula, IFG, and hippocampus at the acute stage (Sihvonen et al., 2016, 2017b). Specific lesion patterns were observed in the left IFG for those amusic patients who recovered over a 6-month post-stroke period and in the right STG, IFG, and insula in those amusic patients who did not show recovery during this time (Sihvonen et al., 2017b). In VBM, the non-recovered amusics also showed additional atrophy (reduction of grey / white matter volume) in the right STG, MTG, insula, and IFG compared to non-amusics and recovered amusics from acute to 6 months post-stroke (Figure 2B). In DTI, non-recovered amusia was also associated with structural damage and later degeneration in multiple right frontotemporal and frontal pathways, including the inferior fronto-occipital fasciculus (IFOF), the arcuate fasciculus (AF), the uncinate fasciculus (UF), and the frontal aslant tract (FAT), as well as interhemispheric tracts, especially the posterior corpus callosum connecting the left and right temporal cortices (Figure 2C, Sihvonen et al., 2017c). Although the acute stage lesion patterns were largely overlapping for pitch-amusia and rhythm-amusia, these deficits showed a partially different longitudinal pattern, with right posterior temporal and right temporoparietal areas implicated in pitch-amusia and right anterior temporal areas and left frontotemporal areas implicated in rhythm-amusia (Sihvonen et al., 2016, 2017b, 2017c). These results suggest that neuroplasticity changes especially in the right hemisphere govern the recovery of pitch-amusia whereas for rhythm-amusia these changes are more bilateral. Functionally, acquired amusia was associated with reduced fMRI activation in many bilateral frontal, temporal, and parietal areas when listening to instrumental music (Figure 2D) whereas the processing of vocal (sung) music was, in turn, better preserved (Sihvonen et al., 2017d). Overall, amusia recovery was linked to increasing activation in left and right frontal and parietal areas during instrumental music listening (Figure 2D) as well as increased functional connectivity in bilateral frontoparietal attention networks.

\subsection{Preservation of singing in aphasia}

The notion that even severely aphasic stroke patients who are unable to produce speech can retain the ability to sing lyrics of familiar songs is one of the classic observations in neurology, dating back to 1740s (Johnson \& Graziano, 2015). However, experimental evidence for this is a surprisingly scarce and mixed, with some case and small-scale group studies in aphasics reporting better singing vs. speaking of familiar song lyrics (Hébert, Racette, Gagnon, \& Peretz, 2003; Jacome, 1984; Straube, Schulz, Geipel, Mentzel, \& Miltner, 2008; Yamadori, Osumi, Masuhara, \& Okubo, 1977) and some not (Prior, Kinsella, \& Giese, 1991; Racette, Bard, \& Peretz, 2006). Interestingly, Racette et al. (2006) found that when aphasic patients were learning novel lyrics by either singing or speaking in unison with an auditory model, they repeated and recalled more words when singing than when speaking whereas no difference was observed between the sung and spoken conditions when repetition and recall were done alone, without the auditory model. Although this study did not directly compare singing in unison to singing alone, the results suggest that choral singing may be an effective tool for speech training. However, the neural mechanisms underlying the potential preservation of sung word production in aphasia have never been studied using structural or functional neuroimaging methods, although a couple of studies have explored this topic in the context of singing-based rehabilitation methods (see section 4.1.2).

\subsection{Preservation of music-evoked emotions and memories in Alzheimer's disease}

In $A D$, there are many striking accounts of how a person with severe dementia who is uncommunicative and mostly unresponsive to the environment can suddenly become animated and aroused when hearing a familiar song (Sacks, 2007). During the last decade, these observations have also received scientific support as experimental studies comparing AD patients and healthy elderly controls have shown that $A D$ patients typically have relatively well-preserved ability to detect basic acoustic changes (e.g., pitch, timbre, rhythm) in music, although higher-level auditory functions, such as melodic contour perception, auditory apperception / scene analysis, and tonal working memory can be impaired (Basaglia-Pappas et al., 2013; Golden et al., 2017; Goll et al., 2011, 2012; Johnson et al., 2011; Ménard \& Belleville, 2009; White \& Murphy, 1998). AD patients are also able to perceive and recognize emotions conveyed by music as well as recognize the melodies and titles of 
familiar songs (Drapeau, Gosselin, Gagnon, Peretz, \& Lorrain, 2009; Hsieh, Hornberger, Piguet, \& Hodges, 2011, 2012; Johnson et al., 2011). Importantly, familiar music has consistently been shown to evoke personal emotions and autobiographical memories as well as enhance mood in AD patients (Basaglia-Pappas et al., 2013; Cuddy, Sikka, \& Vanstone, 2015; El Haj, Antoine, Nandrino, Gély-Nargeot, \& Raffard, 2015; El Haj, Fasotti, \& Allain, 2012; Foster \& Valentine, 2001; Irish et al., 2006; Meilán García et al., 2012).

The neural basis of the preservation of music-evoked emotions and memories in $A D$ is still rather poorly understood. According to findings from VBM studies in dementia cohorts, impaired recognition of musical emotions or familiar songs appears to be associated with the degree of atrophy specifically in the anterior temporal lobe (Hsieh et al., 2011, 2012; Johnson et al., 2011), which is more common in semantic dementia than in AD. Recently, Jacobsen et al. (2015) reported that specific medial frontal areas (anterior cingulate, supplementary motor area), which were found to govern the recognition of familiar songs in young healthy adults ( $N=32$ ) using fMRI, showed minimal cortical atrophy (measured with VBM) and disruption of glucosemetabolism [measured with positron emission tomography (PET)] in the anatomical scans of $A D$ patients $(N=$ 20) with mild-to-moderate dementia. Together, these results suggest that music-evoked memories may tap regions in the brain, which are relatively well preserved in $A D$.

\subsection{Preservation of music in severe amnesia}

In addition to $A D$, some aspects of music may be preserved also in cases of severe amnesia, with both anteroand retrograde memory impairment caused for example by encephalitis or brain injury. Although amnesic patients are typically not able to explicitly recall semantic music-related information (e.g., names of composers, artists or songs), they can nevertheless recognize both familiar (well-known) songs and novel songs after a learning period (Finke, Esfahani, \& Ploner, 2012; Haslam \& Cook, 2002) and may even be able to better recall autobiographical memories after hearing familiar songs (Baird \& Samson, 2014). Amnesic patients who have an active musical background can also retain declarative knowledge of skills related to music playing (Gregory, McCloskey, Ovans, \& Landau, 2016), procedural memory for playing familiar musical pieces (Sacks, 2007), and the ability to learn to play new songs (Cavaco, Feinstein, van Twillert, \& Tranel, 2012; Valtonen, Gregory, Landau, \& McCloskey, 2014). Although the neural mechanisms governing these effects are not known, these findings suggest that recalling and learning of musical information engages brain networks that are distinct (or more widespread) than those involved in other types of episodic and semantic memory.

\section{Songs as a verbal learning tool in stroke and dementia}

\subsection{Musical mnemonics}

One of the key cultural functions of songs has always been to pass on verbal knowledge and folklore. Songs or rhymes are still commonly used today, especially in children, to facilitate the learning of verbal information, such as letters of the alphabet (Alphabet song) or notes of a musical scale (Do-Re-Mi song). Musical mnemonics refers to the idea that music, especially singing, may act as a mnemonic or learning device, providing a structured temporal scaffolding framework that facilitates word learning (Ferreri \& Verga, 2016). Hearing the melody of a well-known song can cue the retrieval of its lyrics (Rubin, 1977), and lyrics are effectively paired with melody also when learning unfamiliar songs (Samson \& Zatorre, 1991; Serafine, Crowder, \& Repp, 1984). In healthy subjects, an enhancement of memory for sung vs. spoken novel verbal material has been reported for the learning and/or delayed recall of connected text, such as song lyrics and sentences (Calvert \& Tart, 1993; Kilgour, Jakobson, \& Cuddy, 2000; Ludke, Ferreira, \& Overy, 2014; Wallace, 1994), and unconnected text, such as word lists (Rainey \& Larsen, 2002; Tamminen, Rastle, Darby, Lucas, \& Williamson, 2017), although some studies have found no differences in performance when comparing the two presentation forms (Racette \& Peretz, 2007; Thaut, Peterson, \& Mclntosh, 2005).

Overall, the mnemonic effect of songs in facilitating verbal learning and memory appears to occur most often when the to-be-learned verbal material is connected text (e.g., phrases or sentences, instead of isolated words) 
and the sung melody is simple in its melodic and rhythmic structure, repetitive, and slower in tempo compared to speech. In general, the melodic and rhythmic patterns of music provide a rich structure that can potentially help in chunking words and phrases, identifying line lengths and stress patterns, and adding emphasis and focus on the surface characteristics of the text (e.g., phonemic structure, phrasing) (Wallace, 1994).

\subsection{Learning and recall of sung vs. spoken material in neurological disorders}

In addition to healthy subjects, the mnemonic effects of songs have been explored also in persons with memory impairment caused by a neurological illness. Thaut et al. gave two groups of multiple sclerosis (MS) patients an auditory word list learning task either in spoken or sung format over multiple learning trials. MS patients showed better overall word memory and word order memory in the sung condition, and this effect was coupled with stronger oscillatory (alpha band) synchronization in bilateral prefrontal areas (Thaut, Peterson, Mclntosh, \& Hoemberg, 2014).

The learning of novel song lyrics has also been studied in AD patients. In the study of Simmons-Stern, Budson \& Ally (2010), AD patients and healthy older adults were visually presented lyrics of unfamiliar children's songs, accompanied by either a sung or a spoken recording of the lyrics. In AD patients, recognition memory was better for the sung than spoken lyrics (Simmons-Stern et al., 2010). A similar memory advantage of sung over spoken lyrics in immediate and/or delayed recall was seen also in two other studies of AD patients (Moussard, Bigand, Belleville, \& Peretz, 2014; Palisson et al., 2015). In the Palisson et al. (2015) study, the sung presentation was also better for recall than a non-musical association (spoken presentation paired with a silent movie sequence), suggesting that this effect seems to be quite specific to music.

In stroke patients, the learning of unfamiliar song lyrics has previously been explored in two small studies of chronic aphasics. In the case study of Hébert et al. (2003), a right hemisphere-lesioned, severely aphasic patient did not show better repetition of unfamiliar song lyrics when presented in sung vs. spoken format. Similarly, in Racette et al. (2006), stroke patients with moderate-to-severe aphasia $(\mathrm{N}=8)$ did not differ in the repetition of unfamiliar song lyrics when they were sung compared to when they were spoken with the melody (sung on syllable /la/) on the background.

Recently, using a larger sample of stroke patients ( $N=31,14$ with mild aphasia) studied longitudinally at acute and 6-month post-stroke stage, we explored the learning and recall of entirely novel narrative stories (written and composed for the study) that were presented in both sung and spoken formats. The task comprised three learning trials and a delayed recall trial. Memory performance on the spoken and sung tasks did not differ at the acute stage, whereas sung stories were learned and recalled better compared to spoken stories at the 6 -month post-stroke stage, both across patients and within the subgroup of mildly aphasic patients (Leo et al., 2018). These sung > spoken recall effects were seen in the second and third learning trials and in the delayed recall trial across all patients (Figure 3A) and in the second and third learning trials in aphasic patients (Figure 3B). Compared to the previous studies in aphasic patients (Hébert et al., 2003; Racette et al., 2006), the significant sung > spoken memory effect observed here is likely due to lower severity of aphasia, larger sample size, more concrete and narrative verbal material, and lack of additional melodic cues in the spoken control condition.

The neural correlates of the sung > spoken memory effect at the 6-month post-stroke stage were also explored using VBM and DTI (deterministic tractography) analyses of MRI data obtained at the same post-stroke time points (for a methodological description, see Supplementary Material). Across all patients, better recall of sung vs. spoken stories in the second learning trial correlated with larger grey matter volume in right anterior temporal areas (STG, MTG) as well as with increased fractional anisotropy (FA) and volume of the right UF, which connects these areas to the right IFG (Figure 3A, Supplementary Table 1). In the aphasic patients (Figure 3B, Supplementary Table 1), the sung > spoken learning effect correlated extensively with larger grey matter volume in left frontal areas [IFG, middle frontal gyrus (MFG), precentral gyrus, anterior cingulate], right temporal (STG, MTG) and limbic (hippocampus) areas, and bilateral parietal [superior parietal lobule (SPL), precuneus] and striatal (caudate) areas. Correspondingly, the sung > spoken learning effect correlated also with increased FA / 
volume in left frontal (FAT) and right frontotemporal (UF), frontoparietal (IFOF), and temporoparietal (posterior AF) tracts in aphasics. No other significant effects were observed.

\section{Music-based interventions in neurological rehabilitation}

\subsection{Music in stroke rehabilitation}

Aesthetic and cultural leisure activities, such as listening to music or dancing, are important for stroke survivors, but unfortunately they are often not able to participate in these due to health issues or inaccessibility of services (O'Connell, Cassidy, O'Neill, \& Moss, 2013). Even in rehabilitation centres, stroke patients typically spend 50$70 \%$ of their daily time not engaged in therapeutic activities or social interaction (Bernhardt, Dewey, Thrift, \& Donnan, 2004; De Wit et al., 2005), and $40-60 \%$ of patients feel that their true rehabilitation needs, especially regarding the emotional and cognitive problems caused by the stroke, are not met by the health care system (McKevitt et al., 2011). During the last 10 years, there has been growing interest in the application of musicbased interventions to support cognitive, motor, and emotional recovery from stroke and to enhance brain plasticity during the recovery period. These interventions can be broadly defined as either receptive (passive) or expressive (active) depending on how music is utilized.

\subsubsection{Receptive music interventions in stroke rehabilitation}

Of different everyday musical activities, music listening is perhaps most easily applicable in the rehabilitation setting. We performed a parallel-group randomized controlled trial (RCT) comparing the long-term effects of a 2-month daily music listening (min 1 hour per day) intervention to an audio book listening intervention and standard care (control group) in acute stroke patients $(N=60)$. Both the audio book and music material was self-selected and the listening was self-implemented with portable players, with the support of music therapists, family members, and nursing staff. The music material comprised mostly of songs with lyrics that were familiar and liked by the patients. Outcome was assessed using neuropsychological tests and mood questionnaires as well as auditory magnetoencephalography (MEG) measurements and sMRI performed at acute, 3-month, and 6-month post-stroke stages.

In a 6-month follow-up, music listening was found to be superior to audio book listening and standard care in improving the recovery of verbal memory and focused attention and reducing depression and confusion (Figure 4A) (Särkämö et al., 2008) as well as in increasing positive mood, relaxation, and motor activity (Forsblom, Särkämö, Laitinen, \& Tervaniemi, 2010). Using MEG, these behavioural gains induced by music listening were also linked functionally to enhanced neural efficiency of auditory encoding, as indexed by the mismatch negativity (MMN), a memory-related electrophysiological response originating from areas in temporal and frontal cortices (Näätänen et al., 2011). The MMN amplitude to pitch changes in the right hemisphere increased more in the music and audio book groups compared to the control group over 6 months (Figure 4B) (Särkämö et al., 2010). Using VBM analyses of sMRI data, music listening was also found to enhance structural neuroplasticity as indicated by increased grey matter volume in spared prefrontal (SFG) and limbic (anterior cingulate, ventral striatum) regions compared to the audio book and control groups (Figure 4C) (Särkämö et al., 2014a).

In addition to the general cognitive and emotional effects, some recent studies have also explored the targeted use of music listening in patients with unilateral spatial neglect (USN), characterized by a deficit in attending to the side opposite a brain lesion (usually left side neglect following right hemisphere damage). To date, two small ( $N=3-19$ ) within-subject studies (Chen, Tsai, Huang, \& Lin, 2013; Soto et al., 2009) have compared the performance of chronic stroke patients in visuospatial attention tasks while listening to (i) pleasant music, (ii) unpleasant music, and (iii) silence / white noise. Compared to the other conditions, pleasant music was found to enhance performance on spatial orienting and scanning tasks and temporarily reduce the ipsilesional attentional bias in USN. Interestingly, this effect was coupled with enhanced mood and arousal as well as with increased functional connectivity between orbitofrontal and parieto-occipital areas, suggesting that the attention benefit of music is likely driven by its emotional impact (Chen et al., 2013; Soto et al., 2009). The longitudinal 
effect of music listening on USN is still unknown, although one subsequent study has reported similar positive long-term effects in two USN cases (Tsai, Chen, Huang, \& Lin, 2013).

\subsubsection{Expressive music interventions in stroke rehabilitation}

In Music-Supported Training (MST), gross and fine movements of the hemiparetic upper extremity are trained through playing keyboards (MIDI piano) and electronic drum pads. In a two-arm RCT, Schneider and colleagues (Schneider, Münte, Rodriguez-Fornells, Sailer, \& Altenmüller, 2010) studied 62 subacute stroke patients who received a 3-week intensive MST intervention and conventional physical therapy or only conventional physical therapy (control group). The MST group showed larger improvement in the speed, precision, and smoothness of fine and gross movements of the hemiparetic upper extremity in standard motor tests compared to the conventional therapy control group as well as to a separate control group $(\mathrm{N}=15)$ who received the same amount of constraint-induced movement therapy (Schneider et al., 2010).

Similar results on motor outcome were obtained also in three subsequent randomized or case-control MST studies of subacute stroke patients ( $\mathrm{N}=$ 9-28; Grau-Sánchez et al., 2014; Van Vugt, Ritter, Rollnik, \& Altenmüller, 2014) and chronic stroke patients ( $N=20$; Ripollés et al., 2016; Rodríguez-Fornells et al., 2012), together also with the enhancement of attention, processing speed, and memory as well as positive effects on mood. In the brain, the behavioural motor gains of MST were coupled with increased motor cortical excitability measured with transcranial magnetic stimulation (TMS) (Amengual et al., 2013; Grau-Sánchez et al., 2014) as well as improved connectivity and functioning of motor cortical areas as indexed by changes in event-related desynchronization / synchronization in EEG (Altenmüller, Marco-Pallares, Münte, \& Schneider, 2009) and activity changes in fMRI on motor and music listening tasks (Ripollés et al., 2016).

In addition to MST, the use of musical instruments has been explored also in USN rehabilitation. Bernardi et al. (2015) compared performance of 11 USN patients when they played a descending $C$ major scale (pressing keys from right to left) either with congruent sound, no-sound, or random sound feedback. Leftward spatial exploration was superior with congruent sound feedback compared to the other conditions, suggesting that the auditorycognitive frame provided by the music scale can help in shifting attention towards the neglected side in USN (Bernardi et al., 2015). The long-term effect of this type of musical intervention program (4-8 weeks) has been explored in two case studies of USN patients (Bodak, Malhotra, Bernardi, Cocchini, \& Stewart, 2014; Guilbert, Clément, \& Moroni, 2016), both of which found that it led to clinical improvement in visuospatial attention tests, with some training-induced gains maintained 4 months post-intervention.

Singing can train speech-motor difficulties at many levels, for example by slowing production rate, increasing connectedness between syllables and words, and using melody as a retrieval cue for words and rhythm to facilitate sound-motor mapping (Wan, Rüber, Hohmann, Schlaug, 2010). In Melodic Intonation Therapy (MIT), speech production is trained by melodically intoning common phrases at slow pace coupled with left handtapping, following a hierarchy of steps that progress from singing to speech. Studies in Broca's aphasics have reported beneficial effects of MIT on connected speech, naming, and repetition (Sparks, Helm, \& Albert, 1974; van der Meulen, van de Sandt-Koenderman, Heijenbrok-Kal, Visch-Brink, \& Ribbers, 2014; Zumbansen, Peretz, \& Hébert, 2014). In neuroimaging studies, the positive effect of MIT in aphasia has been linked to increased activation or neural processing efficiency in speech production in temporal and frontal speech-motor areas, either in the left (Belin et al., 1996; Breier, Randle, Maher, \& Papanicolaou, 2010) or right (Schlaug, Marchina, \& Norton, 2008; Tabei et al., 2016; Wan, Zheng, Marchina, Norton, \& Schlaug, 2014) hemisphere. Findings of MIT-induced neuroplasticity effects in both the left and the right hemisphere make sense given that singing is a highly bilateral process in the brain (Brown et al., 2004; Callan et al., 2006; Özdemir et al., 2006) and that both ipsilateral (left) perilesional areas and contralateral (right) homologous areas are known to play a role in aphasia recovery and in restoring and compensating for the lost speech function (Hartwigsen \& Saur, 2017; Saur et al., 2006). In addition to aphasia, singing-based interventions have been used in dysarthria, a common motor speech disorder after stroke, with two small within-subjects studies reporting benefits in speech motor coordination (e.g., respiration and articulation) and prosody (Kim \& Jo, 2013) and in speech intelligibility and naturalness (Tamplin, 2008). 
There has been increasing interest also in group-based music interventions, which have the added value of being more widely applicable and involving a social interaction element compared to individual-based methods. The MST protocol has been reported to be equally effective motorically and emotionally when applied in individual and pair settings (Van Vugt et al., 2014). Also the effects of choir singing have recently been explored in three small pilot studies. Qualitatively, participating in a community choir is perceived by stroke patients as helpful in the self-management of the social and emotional consequences caused by the illness, such as social isolation, low mood, and communication deficits (Fogg-Rogers et al., 2016). In a within-subjects questionnaire and interview study by Tamplin and colleagues (Tamplin, Baker, Jones, Way, \& Lee, 2013), aphasic stroke patients $(\mathrm{N}=13)$ reported reduced psychological distress and enhanced confidence, mood, motivation, and communication after participating weekly in a community choir for 20 weeks. Recently, in a pilot three-arm RCT of chronic aphasic patients ( $N=23$ ), Zumbansen et al. (2017) compared the effects of weekly choir and drama group interventions to standard care. While no significant outcome effects were observed for the interventions, the level of attendance to the social activities was linked to improved functional communication, and the protocol was found to be feasible.

\subsection{Music in dementia care}

Given the dramatically increasing prevalence of $A D$ and other dementia illnesses (Prince et al., 2013), there is a pressing need for effective ways to support cognitive, emotional, and social functioning in this population, both in persons with dementia (PWDs) and their family members and caregivers. Importantly, as music-induced emotions and memories are often preserved even in more advanced stages of dementia (Basaglia-Pappas et al., 2013; Cuddy et al., 2015; El Haj et al., 2012, 2015; Foster \& Valentine, 2001; Irish et al., 2006; Meilán García et al., 2012), music can be used therapeutically across the dementia spectrum, from mild cognitive impairment $(\mathrm{MCl})$ to severe dementia.

\subsubsection{Receptive music interventions in dementia care}

Emotional and well-being effects. Studies exploring the emotional effects of receptive musical activities in dementia can be broadly divided to those assessing the immediate effect of music listening on mood state during single exposure and those assessing the short-term or long-term effects of more regular exposure to music. Regarding the former, pleasant and stimulating background music has been observed to temporarily reduce anxiety (Irish et al., 2006). Regarding the latter, there are a number of small non-randomized and randomized intervention studies in PWDs with moderate-severe dementia residing in a long-term care facility that have assessed the emotional and social impact of musical leisure activities, primarily utilizing the listening of individualized (preferred) music, over a time period ranging from short (15-30 min) single sessions to multiple weeks. Using observational ratings, these studies have reported short-term beneficial effects of music listening on anxiety (Gerdner, 2005; Sung, Chang, \& Lee, 2010), agitation (Garland, Beer, Eppingstall, \& O'Connor, 2007; Remington, 2002; Ziv, Granot, Hai, Dassa, \& Haimov, 2007), and positive social behaviors and interaction (Ziv et al., 2007).

Recently, there have also been a couple of RCT studies assessing the efficacy of interventions involving regular music listening. In a three-arm RCT by Raglio et al. (2015), 10-week music therapy and music listening interventions were compared to standard care in 120 PWDs of moderate to severe severity living in a nursing home, but no significant effects of the music interventions were observed on behavioural and psychological symptoms of dementia (e.g., depression, anxiety). Innes et al. (Innes, Selfe, Khalsa, \& Kandati, 2016) assessed the effects of two 12-week relaxation programs, one using Kirtan Kriya Meditation and one music listening, in 60 community dwelling older adults with subjective cognitive decline in a two-arm RCT. Both after the intervention period and in a 6-month follow-up, they observed significant improvements in psychological well-being, mood, and sleep quality in both groups, although these were slightly larger in the meditation than music listening group (Innes et al., 2016).

The studies listed above all used music listening interventions implemented by trained research assistants or rehabilitation personnel. We recently performed a study exploring a novel dyadic music coaching intervention in 
which the caregivers (family members and nurses) were trained by a music therapist or singing teacher to use either music listening or singing together with the PWD as a part of daily care. In a three-arm RCT, dyads of PWDs of mild-moderate severity (half living at home, half at a nursing home) and their caregivers ( $N=89)$ were randomized to two 10-week interventions, one utilizing singing and one music listening, and to a standard care control group. Both interventions comprised weekly group training sessions (90 minutes) as well as musical "homework" performed by the dyad at home between the sessions. The interventions entailed identifying which songs were emotionally and autobiographically most important to the PWD and instructing the caregivers on how to utilize them with the PWD in everyday care for different purposes (e.g., relaxation, reminiscence, and vitalization). Outcome was assessed using neuropsychological tests as well as mood and QoL questionnaires performed at baseline, after the intervention, and 6 months later. Compared to standard care, music listening was found to be effective short-term (after the intervention period) in alleviating depressed mood (see Figure $5 \mathrm{~A})$, especially the behavioural signs of depression (agitation, loss of interest), and it also had a positive longterm effect on quality of life (QoL) seen at the 6-month follow-up (Särkämö et al., 2014b, 2016b).

Cognitive effects. Studies assessing the immediate cognitive effects of short-term music exposure (background music) in PWDs have shown that hearing stimulating music can temporarily enhance cognitive performance in tasks of episodic (autobiographical) memory (Cuddy et al., 2015; El Haj et al., 2012, 2015; Foster \& Valentine, 2001; Irish et al., 2006; Meilán García et al., 2012) and verbal fluency (Thompson et al., 2005). Regarding the effects of regular music listening, our previous RCT (see above) showed that music listening had a positive short-term effect on general cognitive status (MMSE) and attention and executive function as well as a longterm enhancing effect on orientation level and remote episodic memory compared to standard care (Figure 5A) (Särkämö et al., 2014). Interestingly, the beneficial cognitive effects of music listening were more evident in PWDs of moderate than mild severity and non-AD-type dementia (Särkämö et al., 2016b). In another three-arm $\mathrm{RCT}$, Cheung and colleagues recently compared active music-with-movement and music listening interventions to a social activity (chatting) intervention (all 6 weeks) in 165 PWDs of moderate severity living in a nursing home and found that music listening enhanced delayed memory recall compared to social activity (Cheung, Lai, Wong, \& Leung, 2018).

\subsubsection{Expressive music interventions in dementia care}

Emotional and well-being effects. Studies exploring the effects of expressive musical activities in dementia have mostly focused either on singing on other group-based musical activities involving a combination of singing, moving to music, and instrument playing (e.g. accompanying songs with percussion instruments). In two RCTs, group-based live musical activities (4-8 weeks) were compared to a reading intervention in mild-moderate dementia ( $N=47$; Cooke, Moyle, Shum, Harrison, \& Murfield, 2010) and to a cooking intervention in moderatesevere dementia ( $N=48$, Narme et al., 2014). The results indicated a general positive effect on emotional wellbeing (e.g., reduced depression and behavioural disorders, improved emotional state) across time, but no significant differences between the music and control interventions (Cooke et al., 2010; Narme et al., 2014). In contrast, the larger $(N=165)$ three-arm RCT of Cheung et al. (2016) found that the music-with-movement intervention was effective in reducing depression compared to control social activity.

The emotional and well-being effects of singing in dementia have thus far been explored in two RCTs and in one non-randomised study. In our own three-arm RCT (see above), the singing intervention (familiar songs sung in a group and in a PWD-caregiver dyadic setting at home) was found to be effective short-term in reducing depression (Figure 5A), especially the physical signs of depression (e.g, lack of energy), as well as long-term in reducing caregiver stress and burden (Figure 5B) (Särkämö et al., 2014, 2016a). In a smaller non-RCT study on mild-moderate PWDs ( $N=20)$, Satoh et al. (2015) also observed that a 6 -month karaoke-based singing training reduced neuropsychiatric symptoms and improved sleep time compared to a control group. Most recently, Pongan et al. (2017) assessed the effects of 12-week choir singing and painting interventions in 59 PWDs with mild AD. Both interventions were reported to reduce anxiety and pain and improve QoL (no difference between the interventions here) whereas only the painting intervention reduced depression (Pongan et al., 2017). Further evidence concerning the social aspects of singing comes from qualitative studies of PWDs and their family carers 
participating in group singing together. These studies have reported high engagement levels and positive effects on wellbeing in PWDs (Camic, Williams, \& Meeten, 2013) as well as improved dyadic and social relationships, identity and mood, and coping with dementia in daily life (Osman, Tischler, \& Schneider, 2016; Unadkat, Camic, \& Vella-Burrows, 2017).

Cognitive effects. The cognitive efficacy of expressive musical leisure activities in dementia has thus far been mapped in four RCTs (Cheung et al., 2018; Narme et al., 2014; Pongan et al., 2017; Särkämö et al., 2014, 2016b) and two non-RCT studies (Maguire, Wanschura, Battaglia, Howell, \& Flinn, 2015; Satoh et al. 2015). In the Narme et al. (2014) RCT, no effects of the music or cooking interventions on general cognitive status were observed, whereas in the Cheung et al. (2015) RCT an enhancement of memory storage and delayed recall performance was observed after the movement-to-music intervention compared to the social activity intervention. In our own RCT, compared to both standard care and to the music listening intervention, the singing intervention had short-term positive effect on verbal working memory (Figure 5B) and it also maintained or improved general cognition, attention and executive function, and remote episodic memory (Figure 5A) (Särkämö et al., 2014). Importantly, the singing-induced enhancement of verbal working memory was seen particularly in PWDs who had mild dementia, suggesting that the memory benefits of singing may be greater in the early stages of the illness. A similar finding was reported also in the Pongan et al. (2017) trial where a general improvement in working memory and executive function was seen in PWDs with mild AD after both singing and painting interventions, but only the singing intervention had a positive impact on verbal memory. Maguire et al. (2015), in turn, found that a 4-month group singing intervention enhanced general cognition and visuospatial processing compared to a music listening intervention in PWDs $(N=45)$ whereas Satoh et al. (2015) reported that psychomotor speed was improved in PWDs after 6 months of karaoke-based singing training. Interestingly, these effects were coupled with decreased parietal activation in an fMRI karaoke task, suggestive of improved neural efficiency of cognitive processing (Satoh et al., 2015).

Finally, Doi et al. (2017) recently reported a large-scale three-arm RCT of older adults with $\mathrm{MCl}(\mathrm{N}=201)$ that compared the cognitive effects of dancing and musical instrument playing interventions ( 40 weeks) to a health education control intervention. The results of this pioneering study showed that both dancing and music playing improved general cognition (MMSE) and that dancing had an additional positive effect on verbal memory (Doi et al., 2017). As $\mathrm{MCl}$ is a precursor to dementia, these findings have important clinical implications as they suggest that musical activities can be used to combat age-related cognitive decline, before the onset of dementia.

\subsection{Music interventions in Parkinson's disease}

In addition to stroke and $A D$, there has been a growing interest towards the use of music in the treatment of Parkinson's disease (PD). Gait impairments, such as slowness of walking and reduced stride length, are one of the hallmark symptoms of PD, and the majority of the music-based interventions in PD have been targeted towards ameliorating these impairments. Rhythmic entrainment, our inherent tendency to time movements to the regular beat of music, has been postulated to can act as an external timer, cueing the execution of movements, and therefore bypassing the defective basal ganglia system in PD (Nombela, Hughes, Owen, \& Grahn, 2013). Evidence from multiple RCTs indicates that music-synchronized gait training can improve gait velocity, stride length, and step cadence (de Bruin et al., 2010; Thaut et al., 1996) and that dance-based interventions (e.g. tango, set dancing) have beneficial effects on endurance, motor impairment, and balance as well as on QoL and social participation in PD patients (Duncan \& Earhart, 2012; Foster, Golden, Duncan, \& Earhart, 2013; Hackney \& Earhart, 2009a, 2009b; Volpe, Signorini, Marchetto, Lynch, \& Morris, 2013).

The rhythmic benefits of music may also extend to vocal-motor behavior in PD. Many PD patients suffer from disorders of speech, such weak or hoarse voice, imprecise articulation, or impaired speech rhythm. Harris and colleagues observed that PD patients exhibited impairments of expressive prosody in normal speech production but not during singing (Harris, Leenders, \& de Jong, 2016). In non-RCT intervention studies, singing-based interventions have been reported to be beneficial for enhancing speech production in PD patients with regards 
to speech prosody, vocal fatigue, phonation, and speech intelligibility and intensity (Di Benedetto et al., 2009; Evans, Canavan, Foy, Langford, \& Proctor, 2012; Tanner, Rammage, \& Liu, 2015). Although these findings are promising, further research is clearly needed to ascertain these effects using larger studies with RCT designs. More research is also needed to assess potential wider benefits of singing on communication, cognitive-motor functions, and QoL in PD (Barnish, Atkinson, Barran, \& Barnish, 2016).

\section{Conclusions and future directions}

During the last decades, the field of neuroscience of music has grown considerably and provided unique and valuable insight into the neural mechanisms that govern the perception, emotional experience, cognitive processing, and motor production of music in the healthy brain. Over the last ten years, this knowledge has increasingly been translated also into the clinical field, sparking new important research on the neural basis of music processing in the abnormally developed, damaged, or degenerating brain as well as on the effects of music-based interventions in neurological rehabilitation. Next, we will briefly summarize the key discoveries in these domains and outline some topics for future research.

Neural basis of amusia. Current structural and functional neuroimaging evidence shows that congenital amusia is underpinned by anomalous recurrent processing in the right frontotemporal network, specifically between the right STG and IFG. Our own research has extended this knowledge to acquired amusia, showing that severe and persistent amusia after stroke is caused by more widespread dysfunction in a network, which includes the same key regions as in congenital amusia (right STG and IFG) but also other right temporal (MTG), insular, and limbic (striatum, hippocampus) areas, as well as multiple right frontotemporal and frontal (IFOF, AF, UF, FAT) and interhemispheric temporal (posterior CC) white matter pathways. Amusia recovery is linked to increasing activity and functional connectivity in bilateral frontoparietal (attention) networks during music listening. More research is still needed to better delineate the specific neural architecture underlying different forms of amusia (e.g. for musical pitch vs. rhythm) and to explore the potential use of singing in amusia rehabilitation.

Preservation of musical abilities in neurological disorders. Music and singing can provide a valuable alternative route to verbal and emotional expression and to memory and self-awareness in many neurological disorders. Aphasic stroke patients who have severe speech production deficits may in some cases retain their ability to produce words through singing, but the prevalence of spared singing in aphasia and the clinical factors and neural mechanisms underlying it are still largely unknown. AD patients often have relatively well-preserved music perception skills, and familiar music has been shown to evoke personal emotions and memories and enhance mood in them. The neural basis of this latter effect is still uncertain but it may be related to the structural preservation of medial prefrontal areas in $\mathrm{AD}$. Also amnesic patients can show preserved music recognition as well as music production and learning skills.

Musical mnemonics. Songs can provide an effective template for the learning of novel verbal material, and there has been increasing interest towards the use of musical mnemonics also in clinical populations. MS patients and $A D$ patients have been observed to recall individual words or song lyrics better when presented in sung than spoken format. In our own study, we found that also stroke patients, especially those with mild aphasia, were able to learn new verbal material (narrative stories) better in sung than spoken format. In VBM and DTI, this sung > spoken learning effect was linked structurally to right anterior temporal areas (STG, MTG) and frontotemporal pathways (UF) across all patients. Importantly, in aphasic patients this effect correlated additionally with left prefrontal areas (IFG, MFG, precentral gyrus, anterior cingulate), right limbic areas (hippocampus), and bilateral parietal (SPL, precuneus) and striatal (caudate) areas as well as with left frontal (FAT) and right fronto- and temporoparietal (IFOF, posterior AF) pathways, suggesting that singing-aided verbal learning in aphasia is based on an extensive bilateral network of areas linked to verbal working memory, speechmotor functions, episodic memory, and attention.

Music-based rehabilitation in stroke. Our own RCT showed that self-implemented music listening after stroke enhances the recovery of verbal memory and focused attention and reduces negative mood and that these gains are linked functionally to enhanced auditory-sensory memory in right frontotemporal areas and structurally to 
increased grey matter volume in prefrontal (SFG) and limbic (anterior cingulate, ventral striatum) areas. In addition, there is emerging and promising evidence on the efficacy of music-based interventions targeted for specific cognitive, motor, and verbal deficits caused by stroke showing that (i) listening to music and playing musical scales can reduce unilateral spatial neglect (at least temporarily); (ii) playing-based rehabilitation (MST) can ameliorate upper-extremity hemiparetic symptoms (deficits in motor control of movements), coupled with enhanced auditory-motor coupling in frontotemporal networks; and (iii) singing-based rehabilitation (MIT) can alleviate aphasia symptoms (deficits in speech production), coupled with bilateral neuroplasticity changes in frontotemporal speech-motor areas. In future, it would be interesting to explore how these music intervention tools can be applied also in group settings to make use of the social-interactive elements that are an essential part of music.

Music-based rehabilitation in Alzheimer's disease. Both receptive and expressive music interventions can have emotional benefits (e.g., reduced anxiety, agitation, and depression) and cognitive benefits (e.g. general cognition, memory) in dementia, although the evidence from RCT studies has been somewhat mixed, with some studies reporting significant benefits compared to standard care / control intervention and some not. Our own RCT in PWDs showed that caregiver-implemented music listening and singing helped maintain general cognition, attention and executive function, and remote episodic memory as well as alleviated depression, but singing was more effective than music listening or standard care in enhancing working memory, especially in the mild stage of dementia, and reducing the psychological burden of caregivers. Collectively, current evidence denotes that music-based interventions can have positive effects of mood across all dementia severity levels, whereas positive effects on cognition are seen primarily in active (expressive) music interventions and mostly in the early stages ( $\mathrm{MCl}$ / mild dementia) of the illness. Aside from one small fMRI study (Satoh et al., 2015), the neural basis for the effects of music in dementia is virtually unexplored, and more studies are needed.

Music-based rehabilitation in Parkinson's disease. During the last decade, the rehabilitative effects of music in PD has been one of the fastest growing domains in this field, and there is now emerging evidence that different music-based motor interventions (music-synchronized gait training, dancing) can be effective in enhancing gait parameters as well as other motor functions (e.g. balance) and general well-being in PD patients. Also singingbased interventions are promising in PD, although evidence is still preliminary. More research is needed also in establishing the non-motor (cognitive, emotional, social) effects of music in PD as well as delineating its neural underpinnings.

All in all, while there has been a lot of exciting progress in uncovering how music processing is impaired / spared in different neurological disorders and how music can be utilized therapeutically in their rehabilitation, there is still a lot of work to be done. First and foremost, it is crucial that the positive findings on the rehabilitative effects of music obtained from individual small studies be replicated and put to test in large-scale clinical trials in order to provide stronger and more robust evidence of clinical efficacy, which is needed before these methods can be systematically implemented in clinical practice. Related to this point, we also need a better and more thorough understanding of the different mechanisms that are driving the efficacy of music. This entails determining how the efficacy of music interventions is mediated by individual (i) person-related factors, such as the musical background (e.g., prior music hobbies, role of music in everyday life) and motivation of the patient; (ii) clinical factors, such as the etiology and stage of the illness and the severity and scope of the deficits; (iii) musical factors, including the type of music and the format and content of the intervention; (iv) therapist-related factors, for example elucidating the difference between music-based interventions conducted by music therapists compared to other health professionals, and how the professional training of the clinician impacts rehabilitation outcomes; and (v) physiological and neural factors. Regarding this latter point, there is a call especially for multimethodological music intervention studies combining behavioural outcome measures with neurophysiological and -endocrinological biomarkers (e.g., autonomic responses, cortisol) as well as structural and functional neuroimaging methods that can better elucidate the neurobiological mechanisms underlying the efficacy of music-based rehabilitation. Together, uncovering the contribution of these factors can help in predicting who benefits from which kind of music intervention and how and why this happens; this, in turn, will 
help in optimizing the delivery of the interventions and tailoring them to meet the individual rehabilitation needs of the patients.

\section{Acknowledgements}

The work reported in this article would not have been possible without the efforts and long-standing support of our colleagues and collaborators. We are particularly indebted to Dr. Mari Tervaniemi, Prof. Taina Autti, and Ms. Vera Leo at University of Helsinki; Prof. Seppo Soinila and Prof. Riitta Parkkola at University of Turku; Prof. Antoni Rodríguez-Fornells and Dr. Pablo Ripollés at University of Barcelona; and music therapist Sari Laitinen at Espoo hospital. We would also like to thank the patients and their carers for participating in the studies and for the staffs of the clinical units for their assistance. TS is very grateful to the Finnish Neuropsychological Society for the nomination and to the Federation of the European Societies of Neuropsychology (FESN) for the awarding of the 2017 Cortex Prize, which led to an invitation to write this review.

Financial support for the work was provided by the Academy of Finland (grants 257077, 277693, 299044), Tyks Research Funding (grant 13944), Finnish Brain Research and Rehabilitation Foundation, Finnish Brain Foundation, Ella and Georg Ehrnrooth Foundation, Signe and Ane Gyllenberg Foundation, Maire Taponen Foundation, Finnish Cultural Foundation, National Doctoral Programme of Psychology, and Jenny and Antti Wihuri Foundation.

\section{References}

Albouy, P., Mattout, J., Bouet, R., Maby, E., Sanchez, G., Aguera, P. E., et al. (2013). Impaired pitch perception and memory in congenital amusia: The deficit starts in the auditory cortex. Brain, 136, 1639-1661.

Alluri, V., Toiviainen, P., Jääskeläinen, I. P., Glerean, E., Sams, M., \& Brattico, E. (2012). Large-scale brain networks emerge from dynamic processing of musical timbre, key and rhythm. Neuroimage, 59, 3677-3689.

Alluri, V., Toiviainen, P., Lund, T. E., Wallentin, M., Vuust, P., Nandi, A. K., et al. (2013). From Vivaldi to Beatles and back: Predicting lateralized brain responses to music. Neuroimage, 83, 627-636.

Altenmüller, E., Siggel, S., Mohammadi, B., Samii, A., \& Münte, T. F. (2014). Play it again, Sam: Brain correlates of emotional music recognition. Frontiers in Psychology, 5, 114.

Altenmüller, E., Marco-Pallares, J., Münte, T. F., \& Schneider, S. (2009). Neural reorganization underlies improvement in stroke-induced motor dysfunction by music-supported therapy. Annals of the New York Academy of Sciences, 1169, 395-405.

Amengual, J. L., Rojo, N., Veciana de Las Heras, M., Marco-Pallarés, J., Grau-Sánchez, J., Schneider, S., et al. (2013). Sensorimotor plasticity after music-supported therapy in chronic stroke patients revealed by TMS. PLoS One, 8, e61883.

Angulo-Perkins, A., Aubé, W., Peretz, I., Barrios, F. A., Armony, J. L., \& Concha, L. (2014). Music listening engages specific cortical regions within the temporal lobes: Differences between musicians and nonmusicians. Cortex, 59, 126-137.

Ayotte, J., Peretz, I., \& Hyde, K. (2002). Congenital amusia: A group study of adults afflicted with a musicspecific disorder. Brain, 125, 238-251.

Ayotte, J., Peretz, I., Rousseau, I., Bard, C., \& Bojanowski, M. (2000). Patterns of music agnosia associated with middle cerebral artery infarcts. Brain, 123, 1926-1938.

Baird, A., \& Samson, S. (2014). Music evoked autobiographical memory after severe acquired brain injury: Preliminary findings from a case series. Neuropsychological Rehabilitation, 24, 125-143. 
Barnish, J., Atkinson, R. A., Barran, S. M., Barnish, M. S. (2016). Potential benefit of singing for people with Parkinson's disease: A systematic review. Journal of Parkinson's Disease, 6, 473-84.

Basaglia-Pappas, S., Laterza, M., Borg, C., Richard-Mornas, A., Favre, E., \& Thomas-Antérion, C. (2013). Exploration of verbal and non-verbal semantic knowledge and autobiographical memories starting from popular songs in Alzheimer's disease. International Psychogeriatrics, 25, 785-795.

Belin, P., Van Eeckhout, P., Zilbovicius, M., Remy, P., François, C., Guillaume, S., et al. (1996). Recovery from nonfluent aphasia after melodic intonation therapy: A PET study. Neurology, 47, 1504-1511.

Bengtsson, S. L., Ullén, F., Ehrsson, H. H., Hashimoto, T., Kito, T., Naito, E., et al. (2009). Listening to rhythms activates motor and premotor cortices. Cortex, 45, 62-71.

Bernardi, N. F., Cioffi, M. C., Ronchi, R., Maravita, A., Bricolo, E., Zigiotto, L., et al. (2017). Improving left spatial neglect through music scale playing. Journal of Neuropsychology, 11, 135-158.

Bernhardt, J., Dewey, H., Thrift, A., \& Donnan, G. (2004). Inactive and alone. Physical activity within the first 14 days of acute stroke unit care. Stroke, 35, 1005-1009.

Blood, A. J., \& Zatorre, R. J. (2001). Intensely pleasurable responses to music correlate with activity in brain regions implicated in reward and emotion. Proceedings of the National Academy of Sciences of the United States of America, 98, 11818-11823.

Bodak, R., Malhotra, P., Bernardi, N. F., Cocchini, G., \& Stewart, L. (2014). Reducing chronic visuo-spatial neglect following right hemisphere stroke through instrument playing. Frontiers in Human Neuroscience, 8 , 413.

Brattico, E., Alluri, V., Bogert, B., Jacobsen, T., Vartiainen, N., Nieminen, S., et al. (2011). A functional MRI study of happy and sad emotions in music with and without lyrics. Frontiers in Psychology, 2, 308.

Breier, J. I., Randle, S., Maher, L. M., \& Papanicolaou, A. C. (2010). Changes in maps of language activity activation following melodic intonation therapy using magnetoencephalography: Two case studies. Journal of Clinical and Experimental Neuropsychology, 32, 309-314.

Brown, S., Martinez, M. J., Hodges, D. A., Fox, P. T., \& Parsons, L. M. (2004). The song system of the human brain. Brain Research: Cognitive Brain Research, 20, 363-375.

Callan, D. E., Tsytsarev, V., Hanakawa. T., Callan. A. M., Katsuhara, M., Fukuyama, H., et al. (2006). Song and speech: Brain regions involved with perception and covert production. Neuroimage, 31, 1327-1342.

Calvert, S. L., \& Tart, M. (1993). Song versus verbal forms for very-long-term, long-term, and short-term verbatim recall. Journal of Applied Developmental Psychology, 14, 245-260.

Camic, P. M., Williams, C. M., \& Meeten, F. (2013). Does a 'Singing Together Group' improve the quality of life of people with a dementia and their carers? A pilot evaluation study. Dementia (London), 12, 157-176.

Cavaco, S., Feinstein, J. S., van Twillert, H., \& Tranel, D. (2012). Musical memory in a patient with severe anterograde amnesia. Journal of Clinical and Experimental Neuropsychology, 34, 1089-1100.

Chen, J. L., Penhune, V. B. \& Zatorre, R. J. (2008). Listening to musical rhythms recruits motor regions of the brain. Cerebral Cortex, 18, 2844-2854.

Chen, M. C., Tsai, P. L., Huang, Y. T., \& Lin, K. C. (2013). Pleasant music improves visual attention in patients with unilateral neglect after stroke. Brain Injury, 27, 75-82.

Cheung, D. S., Lai, C. K., Wong, F. K., \& Leung, M. C. (2018). The effects of the music-with-movement intervention on the cognitive functions of people with moderate dementia: a randomized controlled trial. Aging \& Mental Health, 22, 306-315. 
Cooke, M., Moyle, W., Shum, D., Harrison, S., \& Murfield, J. (2010). A randomized controlled trial exploring the effect of music on quality of life and depression in older people with dementia. Journal of Health Psychology, $15,765-776$.

Cuddy, L. L., Sikka, R., \& Vanstone, A. (2015). Preservation of musical memory and engagement in healthy aging and Alzheimer's disease. Annals of the New York Academy of Sciences, 1337, 223-231.

de Bruin, N., Doan, J. B., Turnbull, G., Suchowersky, O., Bonfield, S., Hu, B., et al. (2010). Walking with music is a safe and viable tool for gait training in Parkinson's disease: The effect of a 13-week feasibility study on single and dual task walking. Parkinson's Disease, 483530.

De Wit, L., Putman, K., Dejaeger, E., Baert, I., Berman, P., Bogaerts, K., et al. (2005). Use of time by stroke patients: A comparison of four European rehabilitation centers. Stroke, 36, 1977-1983.

Di Benedetto, P., Cavazzon, M., Mondolo, F., Rugiu, G., Peratoner, A., \& Biasutti, E. (2009) Voice and choral singing treatment: A new approach for speech and voice disorders in Parkinson's disease. European Journal of Physical and Rehabilitation Medicine, 45, 13-19.

Doi, T., Verghese, J., Makizako, H., Tsutsumimoto, K., Hotta, R., Nakakubo, S., et al. (2017). Effects of cognitive leisure activity on cognition in mild cognitive impairment: Results of a randomized controlled trial. Journal of the American Medical Directors Association, 18, 686-691.

Drapeau, J., Gosselin, N., Gagnon, L., Peretz, I., \& Lorrain, D. (2009). Emotional recognition from face, voice, and music in dementia of the Alzheimer type. Annals of the New York Academy of Sciences, 1169, 342-345.

Duncan, R. P., \& Earhart, G. M. (2012). Randomized controlled trial of community-based dancing to modify disease progression in Parkinson disease. Neurorehabilitation and Neural Repair, 26, 132-143.

El Haj, M., Antoine, P., Nandrino, J. L., Gély-Nargeot, M. C., \& Raffard, S. (2015). Self-defining memories during exposure to music in Alzheimer's disease. International Psychogeriatrics, 27, 1719-1730.

El Haj, M., Fasotti, L., \& Allain, P. (2012). The involuntary nature of music-evoked autobiographical memories in Alzheimer's disease. Consciousness and Cognition, 21, 238-246.

Evans, C., Canavan, M., Foy, C., Langford, R., \& Proctor, R. (2012). Can group singing provide effective speech therapy for people with Parkinson's disease? Arts \& Health, 4, 83-95.

Feigin, V. L., Forouzanfar, M. H., Krishnamurthi, R., Mensah, G. A., Connor, M., Bennett, D. A., et al. (2014). Global and regional burden of stroke during 1990-2010: Findings from the Global Burden of Disease Study 2010. Lancet, 383, 245-254.

Ferreri, L., \& Verga, L. (2016). Benefits of music on verbal learning and memory: How and when does it work? Music Perception, 34, 167-182.

Finke, C., Esfahani, N. E., \& Ploner, C. J. (2012). Preservation of musical memory in an amnesic professional cellist. Current Biology, 22, R591-592.

Fogg-Rogers, L., Buetow, S., Talmage, A., McCann, C. M., Leão, S. H., Tippett, L., et al. (2016). Choral singing therapy following stroke or Parkinson's disease: An exploration of participants' experiences. Disability and Rehabilitation, 38, 952-962.

Ford, J. H., Addis, D. R., \& Giovanello, K. S. (2011). Differential neural activity during search of specific and general autobiographical memories elicited by musical cues. Neuropsychologia, 49, 2514-2526.

Foster, N. A., \& Valentine, E. R. (2001). The effect of auditory stimulation on autobiographical recall in dementia. Experimental Aging Research, 27, 215-228.

Foster, E. R., Golden, L., Duncan, R. P., \& Earhart, G. M. (2013). Community-based Argentine tango dance program is associated with increased activity participation among individuals with Parkinson's disease.

Archives of Physical Medicine and Rehabilitation, 94, 240-249. 
Garland, K., Beer, E., Eppingstall, B., \& O'Connor, D. W. (2007). A comparison of two treatments of agitated behavior in nursing home residents with dementia: simulated family presence and preferred music. American Journal of Geriatric Psychiatry, 15, 514-521.

Gerdner, L. A. (2005). Use of individualized music by trained staff and family: Translating research into practice. Journal of Gerontological Nursing, 31, 22-30.

Golden, H. L., Clark, C. N., Nicholas, J. M., Cohen, M. H., Slattery, C. F., Paterson, R. W., et al. (2017). Music perception in dementia. Journal of Alzheimer's Disease, 55, 933-949.

Goll, J. C., Kim, L. G., Hailstone, J. C., Lehmann, M., Buckley, A., Crutch, S. J., et al. (2011). Auditory object cognition in dementia. Neuropsychologia, 49, 2755-2765.

Goll, J. C., Kim, L. G., Ridgway, G. R., Hailstone, J. C., Lehmann, M., Buckley, A. H., et al. (2012). Impairments of auditory scene analysis in Alzheimer's disease. Brain, 135, 190-200.

Grahn, J. A. \& Rowe, J. B. (2009). Feeling the beat: premotor and striatal interactions in musicians and nonmusicians during beat perception. Journal of Neuroscience, 29, 7540-7548.

Grau-Sánchez, J., Amengual, J. L., Rojo, N., Veciana de Las Heras, M., Montero, J., Rubio, F., et al. (2013). Plasticity in the sensorimotor cortex induced by Music-supported therapy in stroke patients: A TMS study. Frontiers in Human Neuroscience, 7, 494.

Gregory, E., McCloskey, M., Ovans, Z., \& Landau, B. (2016). Declarative memory and skill-related knowledge: Evidence from a case study of amnesia and implications for theories of memory. Cognitive Neuropsychology, $33,220-240$.

Guilbert, A., Clément, S., \& Moroni, C. (2016). A rehabilitation program based on music practice for patients with unilateral spatial neglect: a single-case study. Neurocase, 23, 12-21.

Hackney, M. E., \& Earhart, G. M. (2009a). Effects of dance on movement control in Parkinson's disease: A comparison of Argentine tango and American ballroom. Journal of Rehabilitation Medicine, 41, 475-481.

Hackney, M. E., \& Earhart, G. M. (2009b). Health-related quality of life and alternative forms of exercise in Parkinson disease. Parkinsonism \& Related Disorders, 15, 644-648.

Hall, D. A., Hart, H. C., \& Johnsrude, I. S. (2003). Relationships between human auditory cortical structure and function. Audiology and Neurootology, 8, 1-18.

Harris, R., Leenders, K. L., \& de Jong, B. M. (2016). Speech dysprosody but no music 'dysprosody' in Parkinson's disease. Brain and Language, 163,1-9.

Hartwigsen, G., \& Saur, D. (2017). Neuroimaging of stroke recovery from aphasia - Insights into plasticity of the human language network. Neuroimage, doi: 10.1016/j.neuroimage.2017.11.056.

Haslam, C., \& Cook, M. (2002). Striking a chord with amnesic patients: Evidence that song facilitates memory. Neurocase, 8, 453-465.

Hébert, S., Racette, A., Gagnon, L., \& Peretz, I. (2003). Revisiting the dissociation between singing and speaking in expressive aphasia. Brain, 126, 1838-1850.

Hsieh, S., Hornberger, M., Piguet, O., \& Hodges, J. R. (2011). Neural basis of music knowledge: Evidence from the dementias. Brain, 134, 2523-2534.

Hsieh, S., Hornberger, M., Piguet, O., \& Hodges, J. R. (2012). Brain correlates of musical and facial emotion recognition: Evidence from the dementias. Neuropsychologia, 50, 1814-1822.

Hyde, K. L., Lerch, J. P., Zatorre, R. J., Griffiths, T. D., Evans, A.C., \& Peretz, I. (2007). Cortical thickness in congenital amusia: When less is better than more. Journal of Neuroscience, 7, 13028-13032. 
Hyde, K. L., Zatorre, R. J., Griffiths, T. D., Lerch, J. P., \& Peretz, I. (2006). Morphometry of the amusic brain: A two-site study. Brain, 129, 2562-2570.

Hyde, K. L., Zatorre, R. J., \& Peretz, I. (2011). Functional MRI evidence of an abnormal neural network for pitch processing in congenital amusia. Cerebral Cortex, 21, 292-299.

Innes, K. E., Selfe, T. K., Khalsa, D. S., \& Kandati, S. (2016). Effects of meditation versus music listening on perceived stress, mood, sleep, and quality of life in adults with early memory loss: A pilot randomized controlled trial. Journal of Alzheimer's Disease, 52, 1277-1298.

Irish, M., Cunningham, C. J., Walsh, J. B., Coakley, D., Lawlor, B. A., Robertson, I. H., et al. (2006). Investigating the enhancing effect of music on autobiographical memory in mild Alzheimer's disease. Dementia and Geriatric Cognitive Disorders, 22, 108-120.

Jacobsen, J. H., Stelzer, J., Fritz, T. H., Chételat, G., La Joie, R., \& Turner, R. (2015). Why musical memory can be preserved in advanced Alzheimer's disease. Brain, 138, 2438-2450.

Jacome, D. E. (1984). Aphasia with elation, hypermusia, musicophilia and compulsive whistling. Journal of Neurology, Neurosurgery, and Psychiatry, 47, 308-310.

Janata, P. (2009). The neural architecture of music-evoked autobiographical memories. Cerebral Cortex, 19, 2579-2594.

Janata, P., Birk, J. L., Van Horn, J. D., Leman, M., Tillmann, B., \& Bharucha, J. J. (2002). The cortical topography of tonal structures underlying Western music. Science, 298, 2167-2170.

Janata, P., Tillmann, B., \& Bharucha, J. J. (2002). Listening to polyphonic music recruits domain-general attention and working memory circuits. Cognitive, Affective \& Behavioral Neuroscience, 2, 121-140.

Jerde, T. A., Childs, S. K., Handy, S. T., Nagode, J. C., \& Pardo, J. V. (2011). Dissociable systems of working memory for rhythm and melody. Neuroimage, 57, 1572-1579.

Johnson, J. K., Chang, C-C., Brambati, S. M., Migliaccio, R., Gorno-Tempini, M. L., Miller, B. L., et al. (2011). Music recognition in frontotemporal lobar degeneration and Alzheimer disease. Cognitive and Behavioral Neurology, 24, 74-84.

Johnson, J. K., \& Graziano, A. B. (2015). Some early cases of aphasia and the capacity to sing. Progress in Brain Research, 216, 73-89.

Kester, D. B., Saykin, A. J., Sperling, M. R., O'Connor, M. J., Robinson, L. J., \& Gur, R. C. (1991). Acute effect of anterior temporal lobectomy on musical processing. Neuropsychologia, 29, 703-708.

Kim, S. J. \& Jo, U. (2013). Study of accent-based music speech protocol development for improving voice problems in stroke patients with mixed dysarthria. NeuroRehabilitation, 32, 185-190.

Kleber, B., Veit, R., Birbaumer, N., Gruzelier, J., \& Lotze, M. (2010). The brain of opera singers: Experiencedependent changes in functional activation. Cerebral Cortex, 20,1144-1152.

Koelsch, S. (2014). Towards a neural basis of music-evoked emotions. Trends in Cognitive Science, 14, 131137.

LaCroix, A. N., Diaz, A. F., \& Rogalsky, C. (2015). The relationship between the neural computations for speech and music perception is context-dependent: An activation likelihood estimate study. Frontiers in Psychology, 6, 1138.

LeDoux, J. (2000). Emotion circuits in the brain. Annual Review of Neuroscience, 23, 155-184.

Leo, V., Sihvonen. A J., Linnavalli, T., Tervaniemi, M., Laine, M., Soinila, S., et al. (2018). Sung melody enhances verbal learning and recall after stroke. Annals of the New York Academy of Sciences, doi: 10.1111/nyas.13624. 
Lévêque, Y., Fauvel, B., Groussard, M., Caclin, A., Albouy, P., Platel, H., et al. (2016). Altered intrinsic connectivity of the auditory cortex in congenital amusia. Journal of Neurophysiology, 116, 88-97.

Lévêque, Y., \& Schön, D. (2015). Modulation of the motor cortex during singing-voice perception. Neuropsychologia, 70, 58-63.

Liégeois-Chauvel, C., Peretz, I., Babaï, M., Laguitton, V., \& Chauvel, P. (1998). Contribution of different cortical areas in the temporal lobes to music processing. Brain, 121, 1853-1867.

Liu, F., Jiang, C., Francart, T., Chan, A. H. D., \& Wong, P. C. M. (2017). Perceptual learning of pitch direction in congenital amusia. Music Perception, 34, 335-351.

Loui, P., Guenther, F. H., Mathys, C., \& Schlaug, G. (2008). Action-perception mismatch in tone-deafness. Current Biology, 18, R331-332.

Ludke, K. M., Ferreira, F., \& Overy, K. (2014). Singing can facilitate foreign language learning. Memory \& Cognition, 42, 41-52.

Magee, W. L., Clark, I., Tamplin, J., \& Bradt, J. (2017). Music interventions for acquired brain injury. Cochrane Database of Systematic Reviews, 1, CD006787.

Maguire, L. E., Wanschura, P. B., Battaglia, M. M., Howell, S. N., \& Flinn, J. M. (2015). Participation in active singing leads to cognitive improvements in individuals with dementia. Journal of the American Geriatrics Society, 63, 815-816.

Mandell, J., Schulze, K., \& Schlaug, G. (2007). Congenital amusia: An auditory-motor feedback disorder? Restorative Neurology and Neuroscience, 25, 323-334.

McDermott, O., Crellin, N., Ridder, H. M., \& Orrell, M. (2013). Music therapy in dementia: A narrative synthesis systematic review. International Journal of Geriatric Psychiatry, 28, 781-794.

McKevitt, C, Fudge, N., Redfern, J., Sheldenkar, A., Crichton, S., Rudd, A. R., et al. (2011). Self-reported longterm needs after stroke. Stroke, 42, 1398-1403.

Meilán García, J. J., lodice, R., Carro, J., Sánchez, J. A., Palmero, F., \& Mateos, A. M. (2012). Improvement of autobiographic memory recovery by means of sad music in Alzheimer's disease type dementia. Aging Clinical and Experimental Research, 24, 227-232.

Ménard, M-C., \& Belleville, S. (2009). Musical and verbal memory in Alzheimer's disease: A study of long-term and short-term memory. Brain and Cognition, 71, 38-45.

Méndez Orellana, C. P., van de Sandt-Koenderman, M. E., Saliasi, E., van der Meulen, I., Klip, S., van der Lugt, A., et al. (2014). Insight into the neurophysiological processes of melodically intoned language with functional MRI. Brain and Behavior, 4, 615-625.

Moussard, A., Bigand, E., Belleville, S., \& Peretz, I. (2014). Learning sung lyrics aids retention in normal ageing and Alzheimer's disease. Neuropsychological Rehabilitation, 24, 894-917.

Näätänen, R., Kujala, T., Kreegipuu, K., Carlson, S., Escera, C., Baldeweg ,T., \& Ponton, C. (2011). The mismatch negativity: An index of cognitive decline in neuropsychiatric and neurological diseases and in ageing. Brain, 134, 3435-3453.

Narme, P., Clément, S., Ehrlé, N., Schiaratura, L., Vachez, S., Courtaigne, B., et al. (2014). Efficacy of musical interventions in dementia: Evidence from a randomized controlled trial. Journal of Alzheimer's Disease, 38, 359-369.

Nombela, C., Hughes, L. E., Owen, A. M., \& Grahn, J. A. (2013). Into the groove: Can rhythm influence Parkinson's disease? Neuroscience \& Biobehavioral Reviews, 37, 2564-2570.

Norman-Haignere, S. V., Albouy, P., Caclin, A., McDermott, J. H., Kanwisher, N. G., \& Tillmann, B. (2016). Pitch-responsive cortical regions in congenital amusia. Journal of Neuroscience, 36, 2986-2994. 
Norman-Haignere, S., Kanwisher, N.G., \& McDermott, J.H. (2015). Distinct cortical pathways for music and speech revealed by hypothesis-free voxel decomposition. Neuron, 16, 1281-1296.

O'Connell, C., Cassidy, A., O'Neill, D., \& Moss, H. (2013). The aesthetic and cultural pursuits of patients with stroke. Journal of Stroke and Cerebrovascular Diseases, 22, e404-418.

Olesen, J., Gustavsson, A., Svensson, M., Wittchen, H. U., Jönsson, B., \& CDBE2010 study group (2012). The economic cost of brain disorders in Europe. European Journal of Neurology, 19, 155-162.

Öngür, D., \& Price, J. L. (2000). The organization of networks within the orbital and medial prefrontal cortex of rats, monkeys and humans. Cerebral Cortex, 10, 206-219.

Osman, S. E., Tischler, V., \& Schneider, J. (2016). 'Singing for the Brain': A qualitative study exploring the health and well-being benefits of singing for people with dementia and their carers. Dementia (London), 15, 1326-1339.

Özdemir, E., Norton, A., \& Schlaug, G. (2009). Shared and distinct neural correlates of singing and speaking. Neuroimage, 33, 628-635.

Palisson, J., Roussel-Baclet, C., Maillet, D., Belin, C., Ankri, J., \& Narme, P. (2015). Music enhances verbal episodic memory in Alzheimer's disease. Journal of Clinical and Experimental Neuropsychology, 37, 503-517.

Patel, A. D. (2003). Language, music, syntax and the brain. Nature Neuroscience, 6, 674-681.

Patterson, R. D., Uppenkamp, S., Johnsrude, I. S., \& Griffiths, T. D. (2002). The processing of temporal pitch and melody information in auditory cortex. Neuron, 36, 767-776.

Perani, D., Saccuman, M. C., Scifo, P., Spada, D., Andreolli, G., Rovelli, R., et al. (2010). Functional specializations for music processing in the human newborn brain. Proceedings of the National Academy of Sciences of the United States of America, 107, 4758-4763.

Pereira, C. S., Teixeira, J., Figueiredo, P., Xavier, J., Castro, S. L., \& Brattico, E. (2011). Music and emotions in the brain: Familiarity matters. PLoS One, 6, e27241.

Peretz, I. (2016). Neurobiology of congenital amusia. Trends in Cognitive Sciences, 20, 857-867.

Peretz, I., Brattico, E., Järvenpää, M., \& Tervaniemi, M. (2009). The amusic brain: In tune, out of key, and unaware. Brain, 132, 1277-1286.

Peretz, I., Brattico, E., \& Tervaniemi, M. (2005). Abnormal electrical brain responses to pitch in congenital amusia. Annals of Neurology, 58, 478-482.

Platel, H., Baron, J. C., Desgranges, B., Bernard, F., \& Eustache, F. (2003). Semantic and episodic memory of music are subserved by distinct neural networks. Neuroimage, 20, 244-256.

Pongan, E., Tillmann, B., Leveque, Y., Trombert, B., Getenet, J. C., et al. (2017). Can musical or painting interventions improve chronic pain, mood, quality of life, and cognition in patients with mild Alzheimer's disease? Evidence from a randomized controlled trial. Journal of Alzheimer's Disease, 60, 663-677.

Prince, M., Bryce, R., Albanese, E., Wimo, A., Ribeiro, W., \& Ferri, C. P. (2013). The global prevalence of dementia: A systematic review and meta-analysis. Alzheimer's \& Dementia, 9, 63-75.

Prior, M., Kinsella, G., \& Giese, J. (1990). Assessment of musical processing in brain-damaged patients: Implications for laterality of music. Journal of Clinical and Experimental Neuropsychology, 12, 301-312.

Racette, A., Bard, C., \& Peretz, I. (2006). Making non-fluent aphasics speak: Sing along! Brain, 129, 25712584.

Racette, A., \& Peretz, I. (2007). Learning lyrics: to sing or not to sing? Memory \& Cognition, 35, 242-253.

Rainey, D. W., \& Larsen, J. D. (2002). The effect of familiar melodies on initial learning and long-term memory for unconnected text. Music Perception, 20, 173-186. 
Remington, R. (2002). Calming music and hand massage with agitated elderly. Nursing Research, 51, 317323.

Ripollés, P., Rojo, N., Grau-Sánchez, J., Amengual, J., Càmara, E., Marco-Pallarés, J., et al. (2016). Music supported therapy promotes motor plasticity in individuals with chronic stroke. Brain Imaging and Behavior, 10, 1289-1307.

Raglio, A., Bellandi, D., Baiardi, P., Gianotti, M., Ubezio, M. C., Zanacchi, E., et al. (2015). Effect of active music therapy and individualized listening to music on dementia: A multicenter randomized controlled trial. Journal of the American Geriatrics Society, 63, 1534-1539.

Rodríguez-Fornells, A., Rojo, N., Amengual, J. L., Ripollés, P., Altenmüller, E., \& Münte, T. F. (2012). The involvement of audio-motor coupling in the music-supported therapy applied to stroke patients. Annals of the New York Academy of Sciences, 1252, 282-293.

Rogalsky, C., Rong, F., Saberi, K., \& Hickok, G. (2011). Functional anatomy of language and music perception: temporal and structural factors investigated using functional magnetic resonance imaging. Journal of Neuroscience, 31, 3843-3852.

Rosslau, K., Steinwede, D., Schröder, C., Herholz, S. C., Lappe, C., Dobel, C., et al. (2015). Clinical investigations of receptive and expressive musical functions after stroke. Frontiers in Psychology, 6, 768.

Rubin, D. C. (1977). Very long-term memory for prose and verse. Journal of Verbal Learning and Verbal Behavior, 16, 611-621.

Sacks, O. (2007). Musicophilia: Tales of Music and the Brain. New York: Vintage Books.

Salimpoor, V. N., Benovoy, M., Larcher, K., Dagher, A., \& Zatorre, R. J. (2011). Anatomically distinct dopamine release during anticipation and experience of peak emotion to music. Nature Neuroscience, 14, 257-262.

Samson, S., \& Zatorre, R. J. (1991). Recognition memory for text and melody for songs after unilateral temporal lobe lesion: Evidence for dual encoding. Journal of Experimental Psychology: Learning, Memory, and Cognition, 17, 793-804.

Särkämö, T., Laitinen, S., Numminen, A., Kurki, M., Johnson, J. K., \& Rantanen, P. (2016a). Clinical and demographic factors associated with the cognitive and emotional efficacy of regular musical activities in dementia. Journal of Alzheimer's Disease, 49, 767-781.

Särkämö, T., Laitinen, S., Numminen, A., Kurki, M., Johnson, J. K., \& Rantanen, P. (2016b). Pattern of emotional benefits induced by regular singing and music listening in dementia. Journal of the American Geriatrics Society, 64, 439-440.

Särkämö, T., Pihko, E., Laitinen, S., Forsblom, A., Soinila, S., Mikkonen, M., et al. (2010). Music and speech listening enhance the recovery of early sensory processing after stroke. Journal of Cognitive Neuroscience, 22, 2716-2727.

Särkämö, T., Ripollés, P., Vepsäläinen, H., Autti, T., Silvennoinen, H. M., Salli, E., et al. (2014a). Structural changes induced by daily music listening in the recovering brain after middle cerebral artery stroke: A voxelbased morphometry study. Frontiers in Human Neuroscience, 8, 245.

Särkämö, T., Tervaniemi, M., Laitinen, S., Forsblom, A., Soinila, S., Mikkonen, M., et al. (2008). Music listening enhances cognitive recovery and mood after middle cerebral artery stroke. Brain, 131, 866-876.

Särkämö, T., Tervaniemi, M., Laitinen, S., Numminen, A., Kurki, M., Johnson, J. K., \& Rantanen, P. (2014b). Cognitive, emotional, and social benefits of regular musical activities in early dementia: randomized controlled study. Gerontologist, 54, 634-650. 
Särkämö, T., Tervaniemi, M., Soinila, S., Autti, T., Silvennoinen, H. M., Laine, M., et al. (2009). Cognitive deficits associated with acquired amusia after stroke: A neuropsychological follow-up study. Neuropsychologia, 47, 2642-2651.

Satoh, M., Yuba, T., Tabei, K., Okubo, Y., Kida, H., Sakuma, H., \& Tomimoto, H. (2015). Music therapy using singing training improves psychomotor speed in patients with Alzheimer's disease: a neuropsychological and fMRI study. Dementia and Geriatric Cognitive Disorders, 5, 296-308.

Saur, D., Lange, R., Baumgaertner, A., Schraknepper, V., Willmes, K., Rijntjes, M., et al. (2006). Dynamics of language reorganization after stroke. Brain, 129, 1371-1384.

Schlaug, G., Marchina, S., \& Norton, A. (2008). From singing to speaking: Why singing may lead to recovery of expressive language function in patients with Broca's aphasia. Music Perception, 25, 315-323.

Schneider, S., Münte, T., Rodriguez-Fornells, A., Sailer, M., \& Altenmüller, E. (2010). Music-supported training is more efficient than functional motor training for recovery of fine motor skills in stroke patients. Music Perception, 27, 271-280.

Schön, D., Gordon, R., Campagne, A., Magne, C., Astésano, C., Anton, J. L., et al. (2010). Similar cerebral networks in language, music and song perception. Neuroimage, 51, 450-461.

Schulze, K., Zysset, S., Mueller, K., Friederici, A. D., \& Koelsch, S. (2011). Neuroarchitecture of verbal and tonal working memory in nonmusicians and musicians. Human Brain Mapping, 32, 771-783.

Schuppert, M., Münte, T. F., Wieringa, B. M., \& Altenmüller, E. (2000). Receptive amusia: Evidence for crosshemispheric neural networks underlying music processing strategies. Brain, 123, 546-559.

Sharda, M., Midha, R., Malik, S., Mukerji, S., \& Singh, N. C. (2015). Fronto-temporal connectivity is preserved during sung but not spoken word listening, across the autism spectrum. Autism Research, 8, 174-86.

Serafine, M. L., Crowder, R. G., \& Repp, B. H. (1984). Integration of melody and text in memory for songs. Cognition, 16, 285-303.

Sihvonen, A. J., Ripollés, P., Leo, V., Rodríguez-Fornells, A., Soinila, S., \& Särkämö, T. (2016). Neural basis of acquired amusia and its recovery after stroke. Journal of Neuroscience, 36, 8872-8881.

Sihvonen, A. J., Särkämö, T., Leo, V., Tervaniemi, M., Altenmüller, E., \& Soinila, S. (2017a). Music-based interventions in neurological rehabilitation. Lancet Neurology, 16, 648-660.

Sihvonen, A. J., Ripollés, P., Rodríguez-Fornells, A., Soinila, S., \& Särkämö, T. (2017b). Revisiting the neural basis of acquired amusia: Lesion patterns and structural changes underlying amusia recovery. Frontiers in Neuroscience, 11, 426.

Sihvonen, A. J., Ripollés, P., Särkämö, T., Leo, V., Rodríguez-Fornells, A., Saunavaara, J., et al. (2017c). Tracting the neural basis of music: Deficient structural connectivity underlying acquired amusia. Cortex, 97, 255-273.

Sihvonen, A. J., Särkämö, T., Ripollés, P., Leo, V., Saunavaara, J., Parkkola, R., et al. (2017d). Functional neural changes associated with acquired amusia across different stages of recovery after stroke. Scientific Reports, 7, 11390.

Simmons-Stern, N. R., Budson, A. E., \& Ally, B. A. (2010). Music as a memory enhancer in patients with Alzheimer's disease. Neuropsychologia, 48, 3164-3167.

Skoe, E. \& Kraus, N. (2010). Auditory brain stem response to complex sounds: A tutorial. Ear and Hearing, 31, 302-324.

Soto, D., Funes, M. J., Guzmán-García, A., Warbrick, T., Rotshtein, P., \& Humphreys, G. W. (2009). Pleasant music overcomes the loss of awareness in patients with visual neglect. Proceedings of the National Academy of Sciences of the United States of America, 106, 6011-6016. 
Sparks, R., Helm, N., \& Albert, M. (1974). Aphasia rehabilitation resulting from melodic intonation therapy. Cortex, 10, 303-316.

Stewart, L., von Kriegstein, K., Warren, J. D. \& Griffiths, T. D. (2006). Music and the brain: Disorders of musical listening. Brain, 129, 2533-2553

Straube, T., Schulz, A., Geipel, K., Mentzel, H. J., \& Miltner, W. H. (2008). Dissociation between singing and speaking in expressive aphasia: The role of song familiarity. Neuropsychologia, 46, 1505-1512.

Sung, H. C., Chang, A. M., \& Lee, W. L. (2010). A preferred music listening intervention to reduce anxiety in older adults with dementia in nursing homes. Journal of Clinical Nursing, 19, 1056-1064.

Tabei, K. I., Satoh, M., Nakano, C., Ito, A., Shimoji, Y., Kida, H., et al. (2016). Improved neural processing efficiency in a chronic aphasia patient following melodic intonation therapy: A neuropsychological and functional MRI study. Frontiers in Neurology, 7, 148.

Tamminen, J., Rastle, K., Darby, J., Lucas, R., \& Williamson, V. J. (2017). The impact of music in learning and consolidation of novel words. Memory, 25, 107-121.

Tamplin, J. (2008). A pilot study into the effect of vocal exercises and singing on dysarthric speech. NeuroRehabilitation, 23, 207-216.

Tamplin, J., Baker, F. A., Jones, B., Way, A., \& Lee, S. (2013) 'Stroke a Chord': The effect of singing in a community choir on mood and social engagement for people living with aphasia following a stroke. NeuroRehabilitation, 32, 929-941.

Tanner, M., Rammage, L., \& Liu, L. (2015) Does singing and vocal strengthening improve vocal ability in people with Parkinson's disease? Arts \& Health, 8, 199-212.

Tervaniemi, M., Szameitat, A.J., Kruck, S., Schroger, E., Alter, K., De Baene, W., et al. (2006). From air oscillations to music and speech: Functional magnetic resonance imaging evidence for fine-tuned neural networks in audition. Journal of Neuroscience, 26, 8647-8652.

Thaut, M. H., McIntosh, G. C., Rice, R. R., Miller, R. A., Rathbun, J., \& Brault, J. M. (1996). Rhythmic auditory stimulation in gait training for Parkinson's disease patients. Movement Disorders, 11, 193-200.

Thaut, M. H., Peterson, D. A., \& McIntosh, G. C. (2005). Temporal entrainment of cognitive functions: Musical mnemonics induce brain plasticity and oscillatory synchrony in neural networks underlying memory. Annals of the New York Academy of Sciences, 1060, 243-254.

Thompson, R. G., Moulin, C. J., Hayre, S., \& Jones, R. W. (2005). Music enhances category fluency in healthy older adults and Alzheimer's disease patients. Experimental Aging Research, 31, 91-99.

Trehub, S. E. (2003). The developmental origins of musicality. Nature Neuroscience, 6, 669-673.

Tsai, P. L., Chen, M. C., Huang, Y. T., \& Lin, K. C. (2013). Effects of listening to pleasant music on chronic unilateral neglect: A single-subject study. NeuroRehabilitation, 32, 33-42.

Unadkat, S., Camic, P. M., \& Vella-Burrows, T. (2017). Understanding the experience of group singing for couples where one partner has a diagnosis of dementia. Gerontologist, 57, 469-478.

Valtonen, J., Gregory, E., Landau, B., \& McCloskey, M. (2014). New learning of music after bilateral medial temporal lobe damage: evidence from an amnesic patient. Frontiers in Human Neuroscience, 8, 694.

van der Meulen, I., van de Sandt-Koenderman, W. M., Heijenbrok-Kal, M. H., Visch-Brink, E. G., \& Ribbers, G. M. (2014). The efficacy and timing of melodic intonation therapy in subacute aphasia. Neurorehabilitation and Neural Repair, 28, 536-544.

van der Steen, J. T., van Soest-Poortvliet, M. C., van der Wouden, J. C., Bruinsma, M. S., Scholten, R. J., \& Vink, A. C. (2017). Music-based therapeutic interventions for people with dementia. Cochrane Database of Systematic Reviews, 5, CD003477. 
Van Vugt, F. T., Ritter, J., Rollnik, J. D., \& Altenmüller, E. (2014). Music-supported motor training after stroke reveals no superiority of synchronization in group therapy. Frontiers in Human Neuroscience, 8, 315.

Volpe, D., Signorini, M., Marchetto, A., Lynch, T., \& Morris, M. E. (2013). A comparison of Irish set dancing and exercises for people with Parkinson's disease: A phase II feasibility study. BMC Geriatrics, 13, 54 .

Wallace, W. T. (1994). Memory for music: Effect of melody on recall of text. Journal of Experimental Psychology: Learning, Memory, and Cognition, 20, 1071-1085.

Wan, C. Y., Rüber, T., Hohmann, A., \& Schlaug, G. (2010). The therapeutic effects of singing in neurological disorders. Music Perception, 27, 287-295.

Wan, C. Y., Zheng, X., Marchina, S., Norton, A., \& Schlaug, G. (2014). Intensive therapy induces contralateral white matter changes in chronic stroke patients with Broca's aphasia. Brain and Language, 136, 1-7.

White, D. A., \& Murphy, C. F. (1998). Working memory for nonverbal auditory information in dementia of the Alzheimer type. Archives of Clinical Neuropsychology, 13, 339-347.

Whiteford, K. L., \& Oxenham, A. J. (2018). Learning for pitch and melody discrimination in congenital amusia. Cortex, 103, 164-178.

Yamadori, A., Osumi, Y., Masuhara, S., \& Okubo, M. (1977). Preservation of singing in Broca's aphasia. Journal of Neurology, Neurosurgery, and Psychiatry, 40, 221-224.

Zarate, J. M. (2013). The neural control of singing. Frontiers in Human Neuroscience, 7, 237.

Zatorre, R. J., \& Belin, P. (2001). Spectral and temporal processing in human auditory cortex. Cerebral Cortex, 11, 946-953.

Zatorre, R. J., Belin, P., \& Penhune, V. B. (2002). Structure and function of auditory cortex: Music and speech. Trends in Cognitive Science, 6, 37-46.

Zatorre, R. J., Chen, J. L., \& Penhune, V. P. (2007). When the brain plays music: Auditory-motor interactions in music perception and production. Nature Reviews Neuroscience, 8, 547-558.

Zatorre, R. J., \& Salimpoor, V. N. (2013). From perception to pleasure: Music and its neural substrates. Proceedings of the National Academy of Science of the United States of America, 110, 10430-10437.

Zendel, B. R., Lagrois, M. É., Robitaille, N., \& Peretz, I. (2015). Attending to pitch information inhibits processing of pitch information: the curious case of amusia. Journal of Neuroscience, 35, 3815-3824.

Zentner, M., \& Eerola, T. (2010). Rhythmic engagement with music in infancy. Proceedings of the National Academy of Science of the United States of America, 107, 5768-5873.

Ziv, N., Granot, A., Hai, S., Dassa, A., \& Haimov, I. (2007). The effect of background stimulative music on behavior in Alzheimer's patients. Journal of Music Therapy, 4, 329-343.

Zumbansen, A., Peretz, I., Anglade, C., Bilodeau, J., Généreux, S., Hubert, M., \& Hébert, S. (2017). Effect of choir activity in the rehabilitation of aphasia: a blind, randomised, controlled pilot study. Aphasiology, 31, 879900.

Zumbansen, A., Peretz, I., \& Hébert, S. (2014). The combination of rhythm and pitch can account for the beneficial effect of melodic intonation therapy on connected speech improvements in Broca's aphasia. Frontiers in Human Neuroscience, 8, 592. 


\section{Figures}

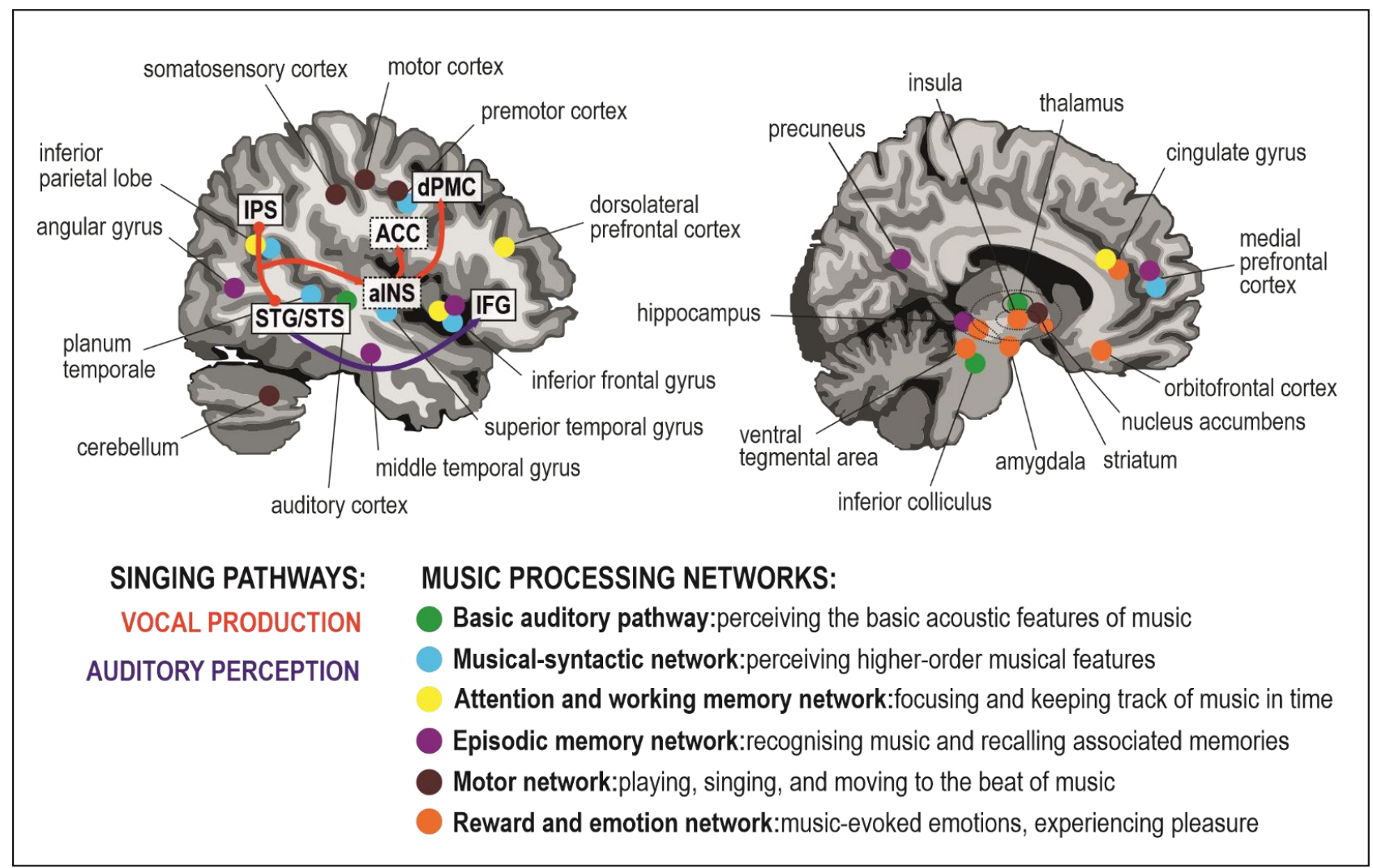

Figure 1. Key brain regions associated with the processing of music overlaid with the main singing-related pathways based on FMRI and PET studies of healthy subjects. Note: although the figure displays the right hemisphere, most of the music processing networks are largely bilateral. ACC, anterior cingulate cortex; alNS, anterior insula; dPMC, dorsal premotor cortex; IFG, inferior frontal gyrus; IPS, intraparietal sulcus; STG/STS, superior temporal gyrus / sulcus. Adapted from Sihvonen et al. (2016a) and Zarate (2013). 


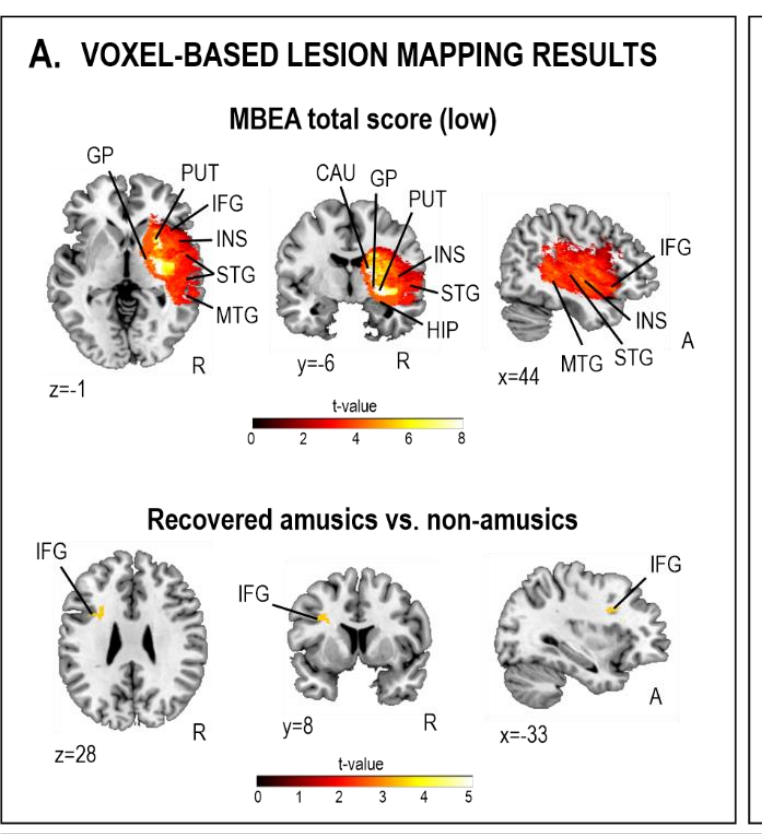

\section{DETERMINISTIC TRACTOGRAPHY RESULTS}

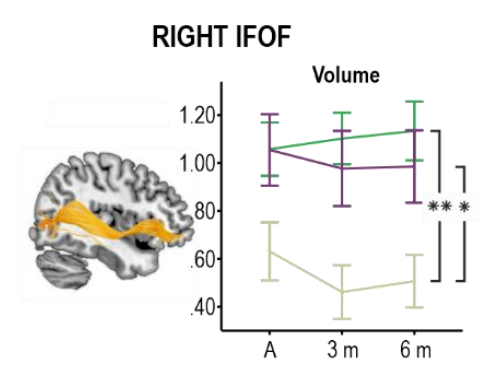

POSTERIOR CC (TAPETUM)

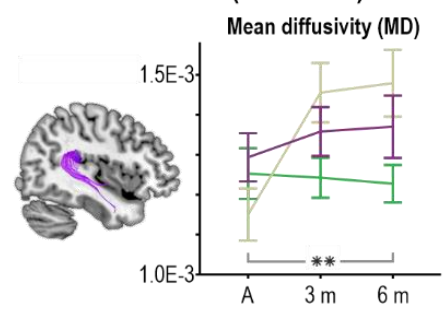

\section{B. VOXEL-BASED MORPHOMETRY RESULTS}
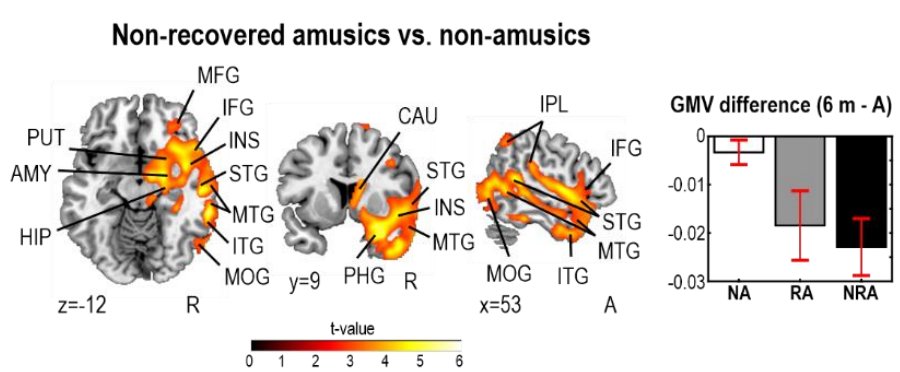

Non-recovered vs. recovered amusics

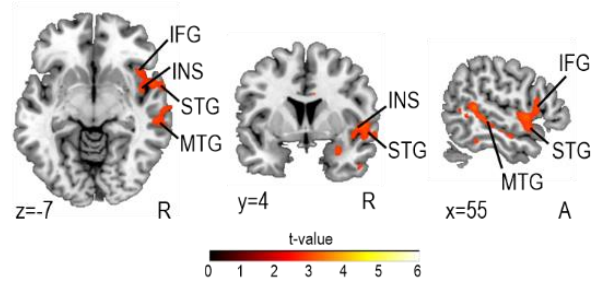

GMV difference $(6 \mathrm{~m}-\mathrm{A})$

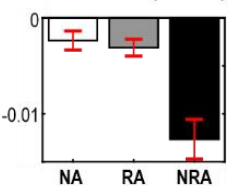

D. fMRI RESULTS (insrumental music - rest)

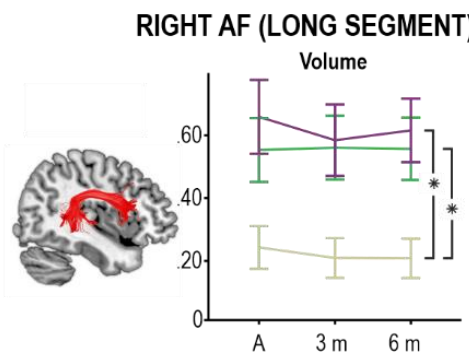

Non-amusic vs. amusic patients $(3 \mathrm{~m})$

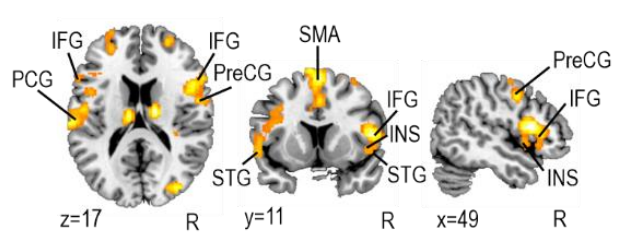

Recovered vs. non-recovered amusic ( $3 \mathrm{~m})$

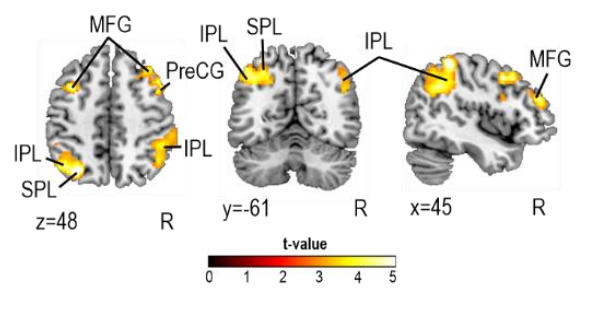

Figure 2. Structural and functional neural correlates of acquired amusia after stroke. (A) Voxel-based lesionsymptom mapping (VLSM) results showing lesion patterns associated with lower scores on the Montreal Battery of Evaluation of Amusia (MBEA) indicative of amusia (upper) and in those amusics showing recovery in a 6 month follow-up compared to non-amusic patients (lower) at acute stage. (B) Voxel-based morphometry (VBM) results (mean \pm SEM) showing decreased grey matter volume (GMV) in non-recovered amusics (NRA) compared to non-amusics (NA, upper) and recovered amusics (RA, lower) over 6 months. (C) Deterministic tractography results (mean $\pm S E M$ ) showing smaller volume of the right inferior fronto-occipital fasciculus (IFOF) and the long segment of the right arcuate fasciculus (AF) at acute (A), 3-month (3 m), and 6-month (6 m) poststroke stages and increasing mean diffusivity (MD) of the posterior corpus callosum (CC, tapetum) over 6 months in non-recovered amusics. (D) fMRI results showing larger activations in non-amusics vs. amusics (upper) and in recovered amusics vs. non-recovered amusics (lower) 3 months post-stroke during listening to instrumental music. AMY, amygdala; A, anterior; CAU, caudate; GP, globus pallidus; HIP, hippocampus; IFG, inferior frontal gyrus; INS, insula; IPL, inferior parietal lobule; ITG, inferior temporal gyrus; MFG, middle frontal gyrus; MOG, middle occipital gyrus; MTG, middle temporal gyrus; PCG, postcentral gyrus; PHG, parahippocampal gyrus; 
PreCG, precentral gyrus; PUT, putamen; R, right; SMA, supplementary motor area; SPL, superior parietal lobule; STG, superior temporal gyrus. Figures adapted from Sihvonen et al. (2017b, 2017c, 2017d). 


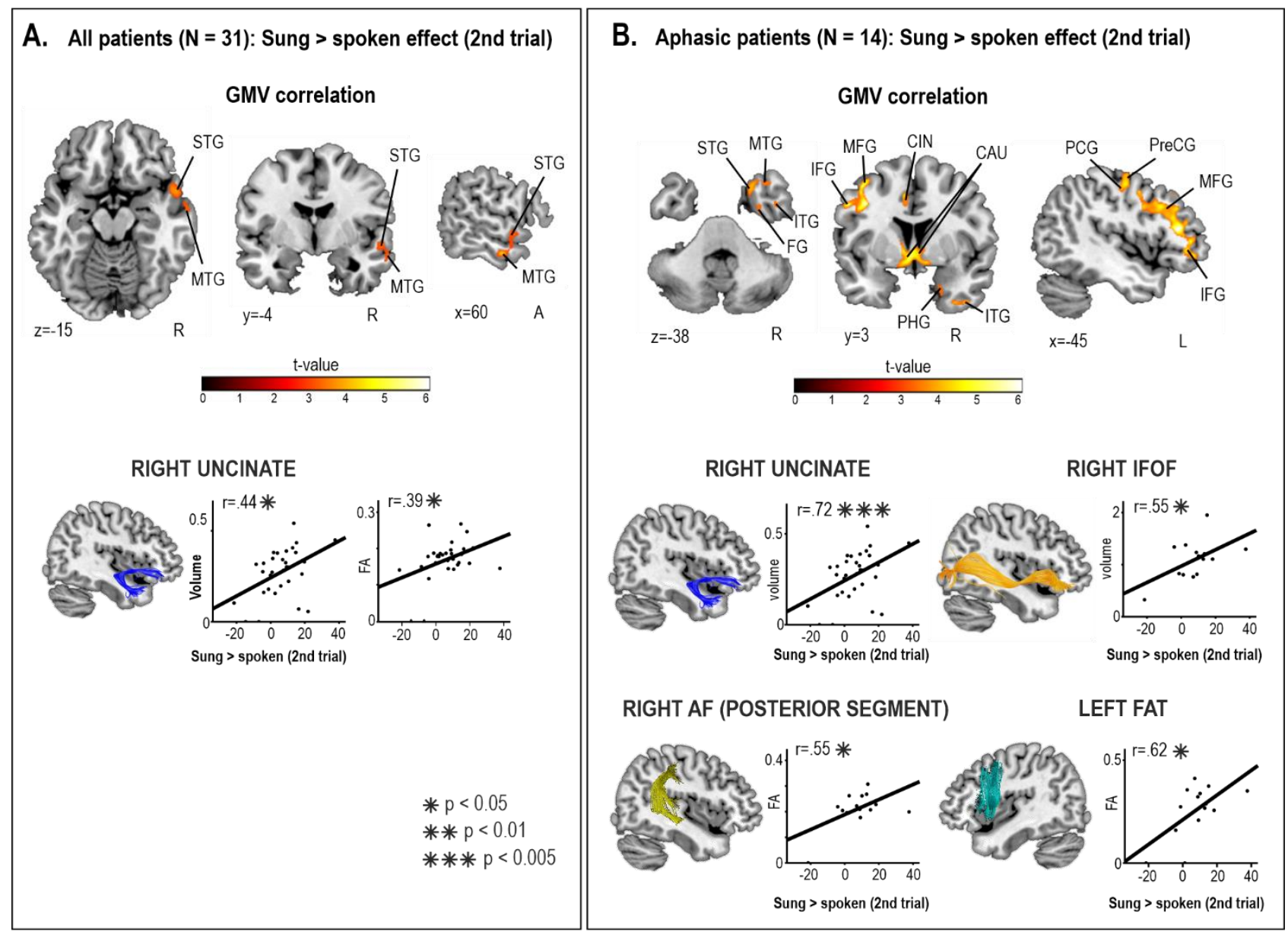

Figure 3. Structural neural correlates of sung story recall in stroke patients. (A) Voxel-based morphometry (VBM) and deterministic tractography results across patients $(N=31)$ showing a correlation between the sung > spoken effect in the $2^{\text {nd }}$ learning trial of the task and grey matter volume (GMV) in right anterior temporal areas (upper) and the volume and fractional anisotropy (FA) of the right uncinate (lower). (B) The same analyses within aphasic patients $(N=14)$ showing a correlation between the sung > spoken learning effect and GMV in left prefrontal, left anterior cingulate, right inferior and medial temporal, and bilateral striatal areas (upper) and the volume / FA of the left frontal aslant tract (FAT), right uncinate, right inferior fronto-occipital fasciculus (IFOF), and the posterior segment of the right arcuate fasciculus (AF) (lower). See Supplementary Material for details. A, anterior; FG, fusiform gyrus; CAU, caudate; CIN, cingulate; IFG, inferior frontal gyrus; ITG, inferior temporal gyrus; L, left; MFG, middle frontal gyrus; MTG, middle temporal gyrus; PCG, postcentral gyrus; PHG, parahippocampal gyrus; PreCG, precentral gyrus; R, right; STG, superior temporal gyrus. 


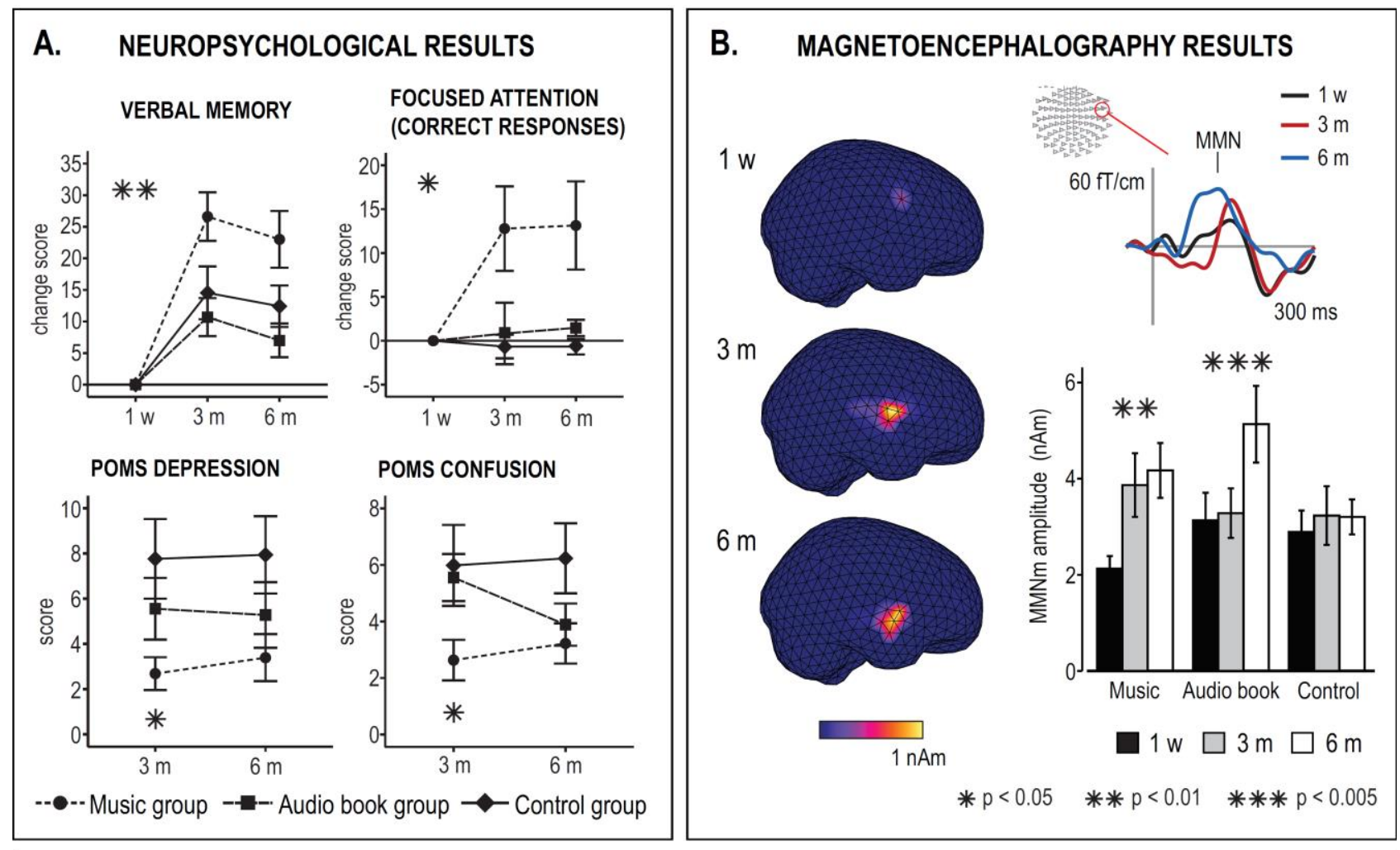

C. VOXEL-BASED MORPHOMETRY RESULTS
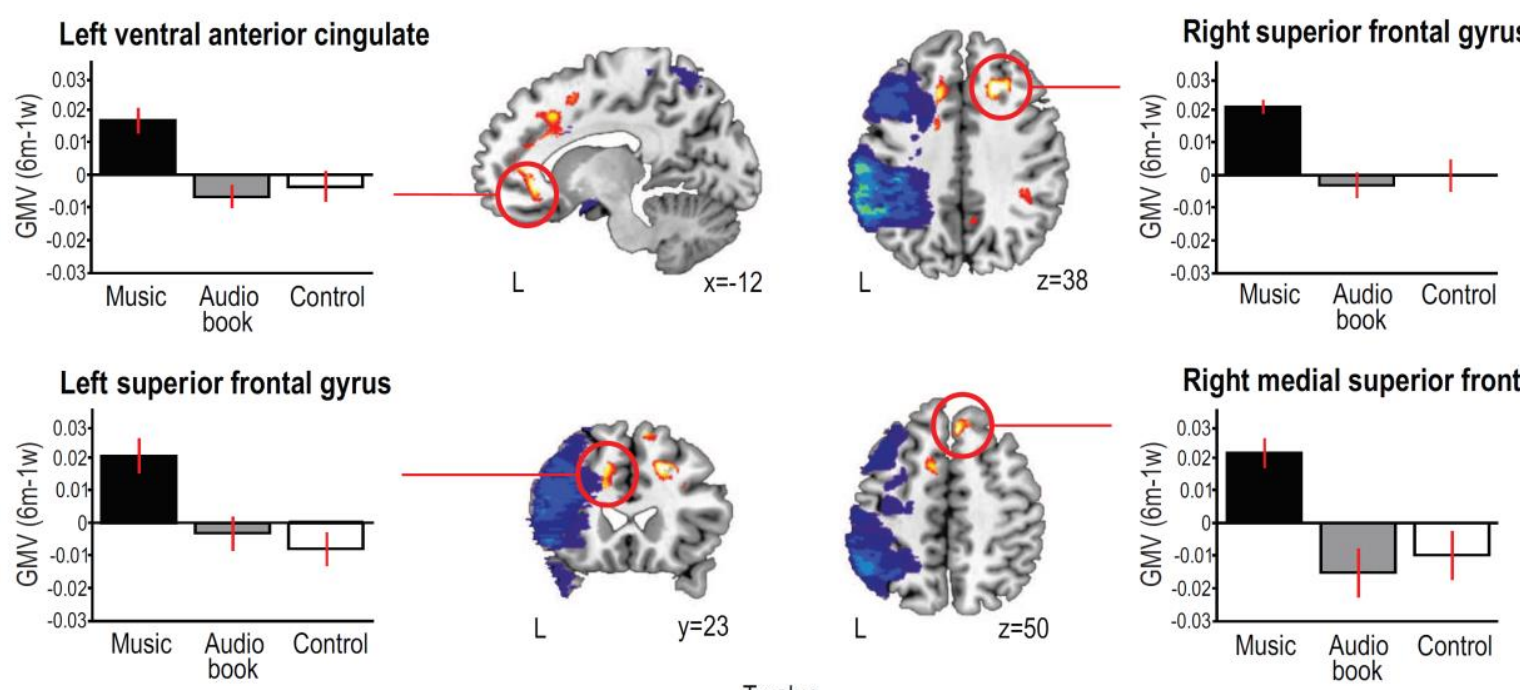

Figure 4. Cognitive, emotional, and neural effects of daily music listening (music group), audio book listening (audio book group), and standard care (control group) 1 week ( $1 \mathrm{w}), 3$ month $(3 \mathrm{~m})$, and 6 months $(6 \mathrm{~m})$ after stroke. (A) Neuropsychological results (mean \pm SEM) showing improved recovery of verbal memory and focused attention (change scores from the 1 week baseline) and less depression and confusion in the music group compared to the audio book and control groups. (B) Magnetoencephalography (MEG) group results (mean \pm SEM) showing increased right hemisphere mismatch negativity (MMN) responses to pitch changes in the music and audio book groups compared to the control group. (C) Voxel-based morphometry (VBM) results of MRI data from patients with left hemisphere damage (lesion areas in blue-green), showing larger grey matter volume (GMV) increases (mean \pm SEM) in prefrontal and limbic areas in the music group compared to the audio book and control groups. $L=$ left hemisphere. Figures adapted from Särkämö et al. $(2008,2010,2014 a)$. 
A. COMMON EFFECTS OF SINGING AND MUSIC LISTENING

Attention \&

Executive function

Orientation

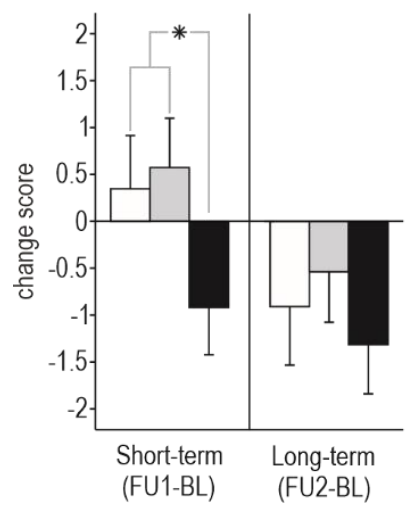

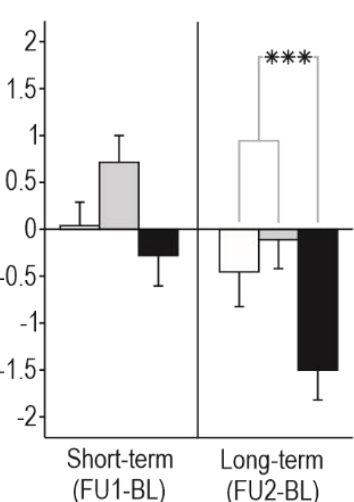

(FU1-BL) (FU2-BL)
Depression (CBS)

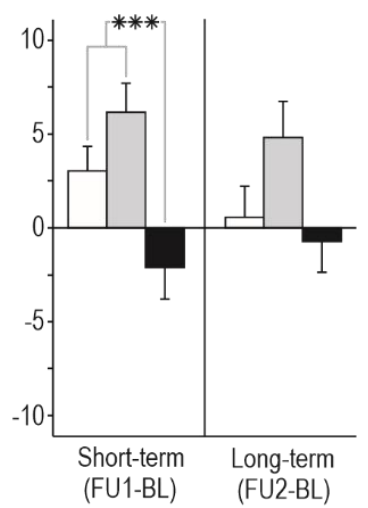

B. SELECTIVE EFFECTS OF SINGING

Verbal working memory

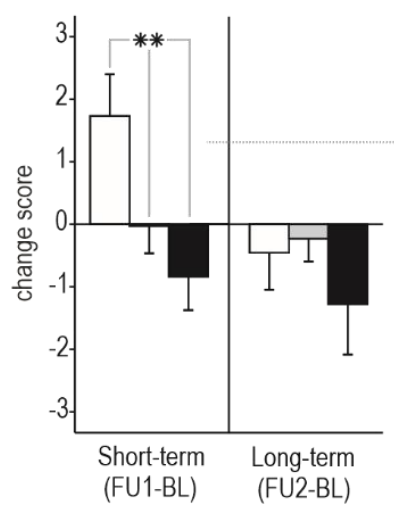

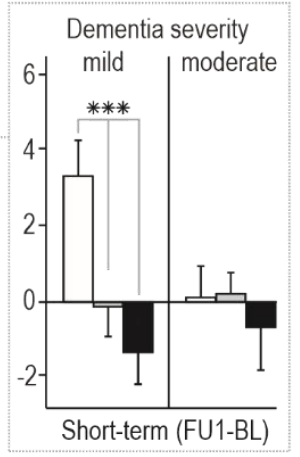

Short-term (FU1-BL)
Caregiver burden (ZBI)

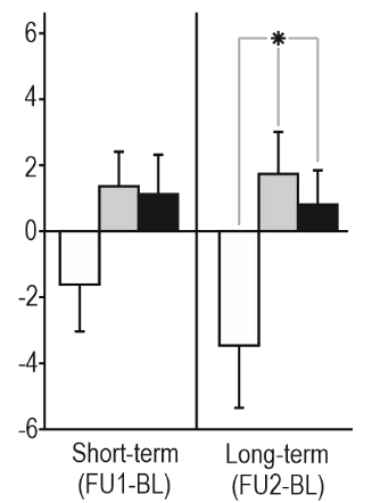

Singing group

Music listening group

Control group

**** $p<0.005$

*** $p<0.01$

Figure 5. Positive cognitive and emotional verbal changes (mean \pm SEM) in PWDs after a 10-week music coaching intervention involving either music listening or singing. (A) Shared effects of both music interventions compared to standard care. (B) Selective effects of singing compared to music listening and standard care. Both short-term [from baseline (BL) to immediate post-intervention follow-up 1 (FU1)] and long-term [from BL to 6 month post-intervention follow-up 2 (FU2)] are shown. CBS = Cornell-Brown Scale, ZBI = Zarit Burden Interview . Adapted from Särkämö et al. (2014b, 2016a). 